University of San Diego

Digital USD

2007-06-18

\title{
Adapted Physical Education Enrollment Issues and Exercise Mediators for Students with Disabilities in San Diego County Community Colleges
}

Toni M. Pfister EdD

University of San Diego

Follow this and additional works at: https://digital.sandiego.edu/dissertations

Part of the Leadership Studies Commons

\section{Digital USD Citation}

Pfister, Toni M. EdD, "Adapted Physical Education Enrollment Issues and Exercise Mediators for Students with Disabilities in San Diego County Community Colleges" (2007). Dissertations. 776.

https://digital.sandiego.edu/dissertations/776

This Dissertation: Open Access is brought to you for free and open access by the Theses and Dissertations at Digital USD. It has been accepted for inclusion in Dissertations by an authorized administrator of Digital USD. For more information, please contact digital@sandiego.edu. 


\title{
ADAPTED PHYSICAL EDUCATION ENROLLMENT ISSUES AND EXERCISE MEDIATORS FOR STUDENTS WITH DISABILITIES IN SAN DIEGO COUNTY COMMUNITY COLLEGES
}

\author{
By
}

Toni M. Pfister

A dissertation submitted in partial fulfillment

Of the requirements for the degree of

Doctor of Education University of San Diego

June 18, 2007

\section{Dissertation Committee}

Fred J. Galloway, Ed.D., Chair Lee Williams, Ph.D., Member Mary Woods Scherr, Ph.D., Member 
(C) Copyright by Toni M. Pfister 2007

All Rights Reserved

Reproduced with permission of the copyright owner. Further reproduction prohibited without permission. 


\section{ABSTRACT}

Most community colleges in California offer adapted physical education (APE) courses specifically designed to assist people with disabilities and chronic diseases in adapting and maintaining exercise programs. However, little is known about those eligible to enroll in these courses as well as their participation profiles; as such, the primary purpose of this study was to determine why some eligible community college students with disabilities do not enroll in APE courses as well as to determine what relationship demographics and exercise participation profiles have on physical activity participation.

Data for this study was gathered through a web-based survey of 163 college students with disabilities enrolled in eight community colleges in Southern California. Results clearly indicated that students with disabilities were significantly more likely to have taken a regular PE class (36.8\%) than an APE class (22.1\%); the three most popular reasons for not taking an APE class were that students exercised on their own, attended regular PE, or were not aware that APE was being offered. In addition, a strong relationship was found between the number of APE or PE courses enrolled in and semesters of college completed as well as the decisional balance score. Although highly intuitive, these findings suggest that the longer students are in school the greater their chance of completing some type of physical education course and those students who see more advantages than disadvantages in exercise are also more likely to enroll in a physical activity course. Regression analysis was also used to show that both decisional balance and exercise self-efficacy were important predictors of the stage of exercise change score. 
Although a number of policy recommendations follow from the results of this study, the two most important involve applying and assessing the APE promotion techniques listed by the respondents to increase participation in APE classes, as well as conducting a longitudinal analysis to examine how APE participation changes future attitudes about exercising. In this manner, schools can use these results to both promote APE classes to those that have never enrolled and for those that have, provide evidence that the classes had real long-term value. 


\section{DEDICATION}

This educational crossing is dedicated to two people who gave their love, support, and at times, their own freedom, to their daughter who was born with a developmental disability. I would like to dedicate this project to my Uncle Wayne Elwell and the memory of my Aunt Maxine Elwell for the love and nurture they provided to their daughter since her birth on October 6,1943. They did this at a time when services and legal rights were not as well established as they are now in the twenty first century. After the death of my aunt in 1995, my uncle provided a whole new life to Loretta where she was able to first benefit from county programs and services that were not even conceived of when she was a child. At the age of 52, Loretta was engaged with new experiences and interactions at a county-funded educational center, evening learning how to take a bus to and from school. It had been a very long time since she had a life to enjoy outside of her home and family.

It was through the examples set by Maxine and Wayne Elwell, and that of my whole family, which I came to believe I might be so honored as to touch the lives of those with disabilities. 


\section{ACKNOWLEDGEMENTS}

There are many people whose guidance and support helped make the dissertation process manageable and even, at times, exciting.

Every time I left my dissertation advisor's office, I left inspired. Just as a good coach inspires his players to reach deeper inside, envision the finish line, and persevere to the end, I always walked out of Dr. Fred Galloway's office with an extra bounce of dissertation energy and more focus on the project. I never left discouraged or with any doubts. His high-energy level and enthusiastic assistance with the study design, data interpretation, and results discussion were a motivating factor in the completion of this project. A visit with Dr. Galloway was like a refreshing bottle of Torero-ade that kept me from bonking.

My dissertation committee was a well rounded team, where each member played a strong position. Dr. Williams' guidance began three years ago when I was enrolled in his Survey course. He helped me design a questionnaire that I continued to improve upon and mold into the final version that was used for my research study. The guidance Dr. Williams provided throughout the process, from infancy to final draft, demonstrated the thought and care he provides to students under his tutelage. Another faculty member who provided thoughtful insight into my proposal drafts was Dr. Athena Perrakis. Dr. Perrakis' impeccable writing style was a gift to doctoral students when she came aboard U.S.D. during my second year of study. Her ability and willingness to help me improve my writing was a grand addition to the dissertation team. In addition, I am grateful for Dr. Mary Scherr's assistance with editing the final chapters and for agreeing to step in when Dr. Perrakis was on maternity leave. The time and effort Dr. Scherr spent to help 
me smooth my writing and clearly explain my ideas were appreciated. She provided a source of motivation when I needed it - before the final peak.

In addition to the faculty at USD, there were others without whom this trip would have been impossible. Looking back to the beginning of this journey, my family and friends seemed a bit amazed that I was loading up my backpack and heading back for more educational training. Still, they came through with the support and encouragement I needed to make it through five years of higher education. Though sometimes it felt like my personal life was on hold, my parents, family, and friends stayed in the game with me, tolerating my pensive moods and preoccupied schedule. I thank you all for offering the sustenance I needed and look forward to spending more time sharing your lives and supporting your endeavors.

And lastly, there are those people who will never know how much their auditory distraction kept me from feeling too lonely during long days at the computer or solitary rides through San Diego. So, a shout goes out to John, Paul, George, Ringo, Cheryl, Eric, Steven, Jack and Bono for always being there when I needed to hear a friendly voice. Recognition must also go to Greg LeMond for inspiring my bike and Lance Armstrong for inspiring me, especially during July, 2003, 2004, and 2005. Though, I sat on a desk chair many days when I wanted to be sitting on my bike, cycling offered one modality for keeping my sanity when barraged with reading, writing, and editing tasks. Ride on! 


\section{TABLE OF CONTENTS}

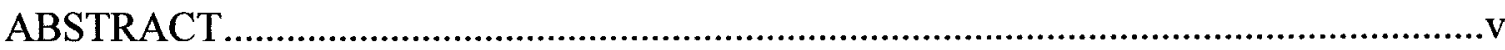

DEDICATION

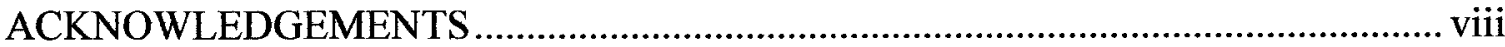

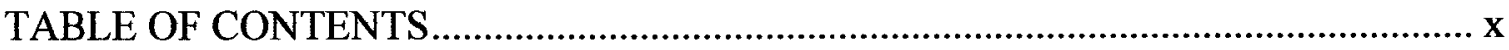

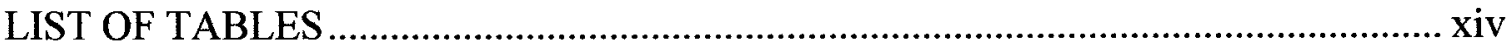

\section{CHAPTER}

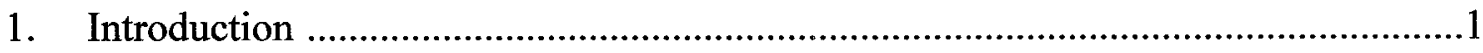

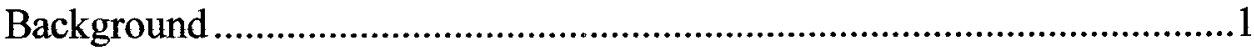

Statement of the Problem .........................................................................5

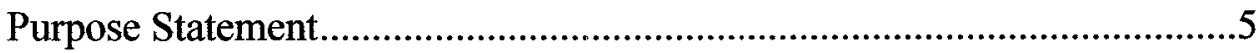

Research Questions ........................................................................ 7

Significance of the Study ...................................................................

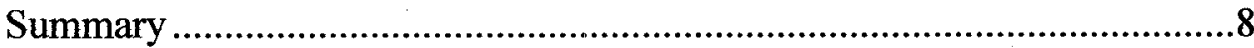

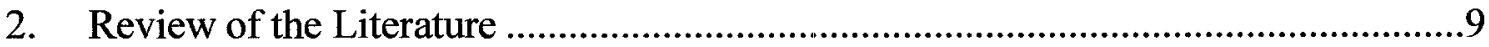

Adapted Physical Education in the California Community Colleges ..........9

History of the California Community College System ...................9

The Role of Legislation ...........................................................10

Meeting the Physical Education Requirement.............................11

Physical Activity Issues .....................................................................13

Rates of Physical Activity........................................................13

Benefits of Physical Activity ...................................................17

Promoting a Behavior Change .................................................19

The Transtheoretical Model of Health Behavior Change .........................19

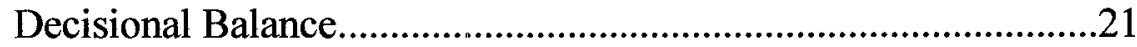

Barriers..............................................................................21

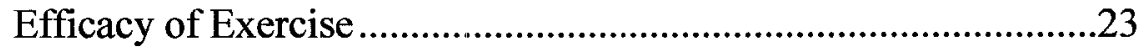

Self-efficacy expectations.............................................23

Outcome expectations.................................................24

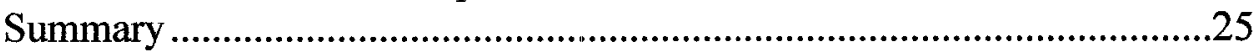

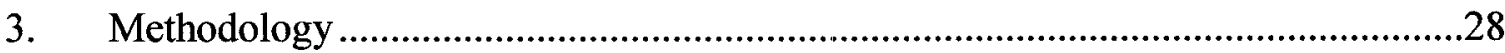

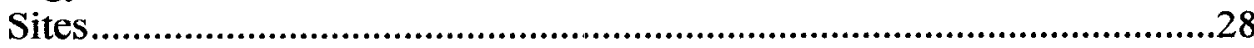

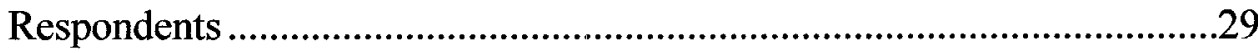

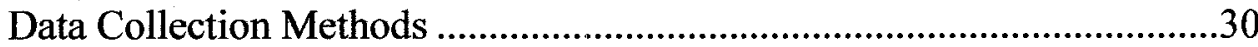

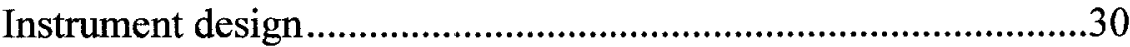

Stages of exercise change mode .................................................

Exercise self-efficacy ............................................................. 


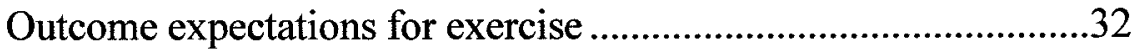

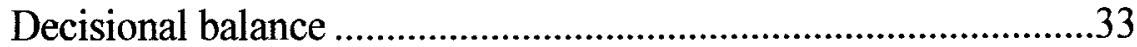

Pre-testing Procedures .........................................................................33

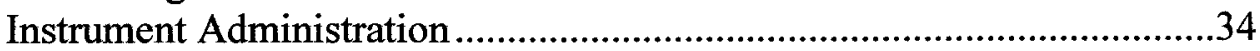

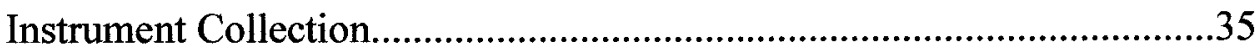

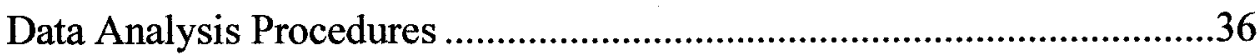

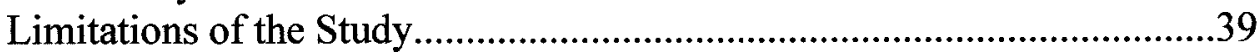

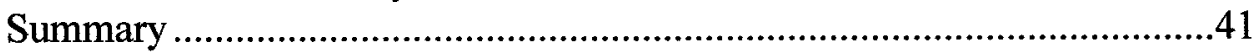

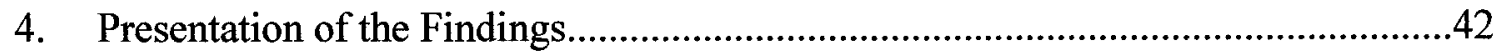

Survey Collection and Time Table ......................................................42

Population Characteristics ...................................................................43

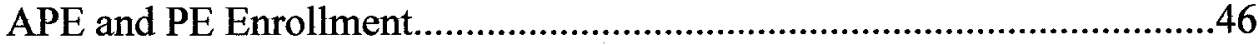

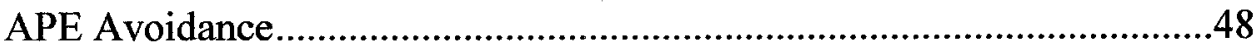

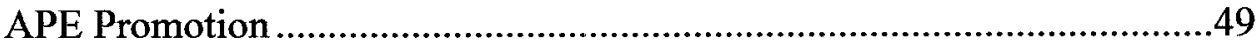

Colleges With and Without APE ........................................................50

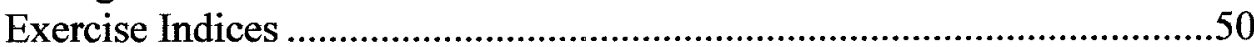

Outcome expectations for exercise .........................................50

Descriptive statistics for the four exercise scales ........................51

APE, PE, both, or neither...........................................................52

Indicators of Physical Education Enrollment ........................................56

5. Summary, Implications, and Recommendations ...............................................63

Summary of the Research Design.....................................................63

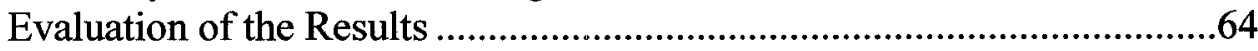

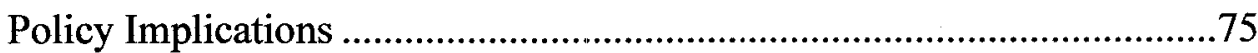

Recommendations for Future Research ............................................76

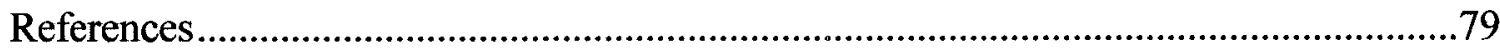

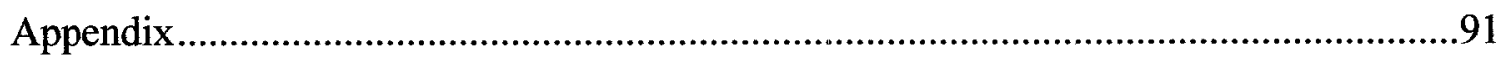

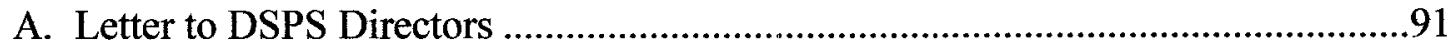

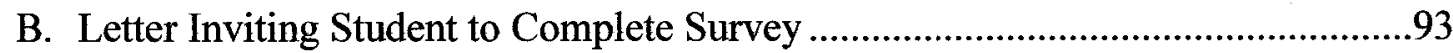

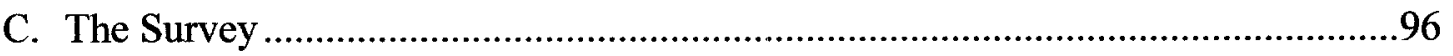

D. The Survey with Distribution of Responses ..............................................109

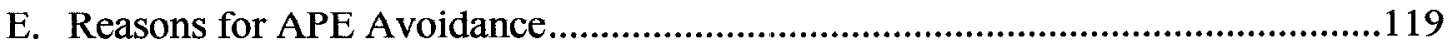




\section{LIST OF TABLES}

Table 1. Survey Return Rates

p. 43

$\begin{array}{ll}\text { Table 2. Respondent Demographics } & \text { p. } 44\end{array}$

$\begin{array}{lr}\text { Table 3. College Experience } & \text { p. } 46\end{array}$

Table 4. Frequency Statistics for Future Plans to Take APE p. 47

$\begin{array}{ll}\text { Table 5. Frequency Statistics for Future Plans to Take PE } & \text { p. } 47\end{array}$

$\begin{array}{ll}\text { Table 6. Top Five Reasons for APE Avoidance } & \text { p. } 48\end{array}$

Table 7. Descriptive Statistics for Exercise Variables $\quad$ p. 51

Table 8. Percent of Participants in Each Stage of Exercise Change p. 52

Table 9. t-Test Comparison of Those Who Have Taken APE vs. Those Who Have $\begin{array}{ll}\text { Not } & \text { p. } 53\end{array}$

Table 10. t-Test Comparison of Those Who Have Taken Regular PE vs. Those Who Have Not

Table 11. t-Test Comparison of Those Students Who Had Taken Neither APE nor PE vs. Those Students Who Had Taken Both APE and PE p. 55

Table 12. t-Test Comparison of Those Students Who Had Taken Neither APE nor PE vs. Those Students Who Had Taken Only PE

Table 13. t-Test Comparison of Those Students Who Had Taken APE and PE vs. Those Students Who Had Taken Only PE

Table 14. Regression Analyses for Number of APE and PE courses taken p. 58

Table 15. Regression Analysis for Stage of Exercise Change p. 59

Table 16. Regression Analysis for Exercise Self-Efficacy $\quad$ p. 60

Table 17. Regression Analysis for Decisional Balance of Exercise p. 61

Table 18. Regression Analysis for Outcome Expectations for Exercise p. 62 


\section{Chapter 1}

\section{Introduction}

In order to improve health and reduce disease risk, American adults are encouraged to exercise on a regular basis. More specifically, they are encouraged to participate in 30 minutes or more of moderate activity on most, if not all, days (American College of Sports Medicine [ACSM], 2000). For those who desire weight loss, an increase to 90 minutes of exercise several times per week is suggested for goal attainment (ACSM).

This emphasis on the need for regular physical activity results, in part, from the fact that an increasing number of Americans are at risk for health problems (Heath, 1997) and age-related declines in physical ability (Carlson, 1999) associated with a sedentary lifestyle. In fact, inactivity is a primary risk factor for coronary artery disease (ACSM, 2000), the second leading cause of death in the United States (Centers for Disease Control and Prevention [CDCP], 2004) and is implicated in certain cancers, such as cancer of the colon (ACSM). However, only 33\% of non-disabled adults engage in regular exercise. It is estimated that even fewer (16\%) of adults with disabilities exercise on a regular basis (CDCP). Due to insufficient physical activity, persons with disabilities are less likely than adults without disabilities to reap the benefits of physical activity (Heath). Sedentary individuals with disabilities may be at even greater risk of death from heart disease, obesity, non-insulin dependent diabetes, hypercholesterolemia, hypertension, and certain cancers than their non-disabled counterparts (Pitetti, 1993). In fact, obesity rates among adults with disabilities are higher (24.9\%) than adults without disabilities (15.1\%; Weil, 2002). Other secondary consequences of inactivity for persons 
with chronic disease or disability may include reduced fitness levels, osteoporosis, impaired circulation possibly leading to thrombus, diminished sense of worth, reduced opportunity for normal social interactions, and greater dependence on others for activities of daily living (Durstine, 2000).

At times, these individuals' sedentary lifestyle may have less to do with lifestyle choices than with the lack of accessible facilities, equipment (Guthrie, 1999; Seidler, 1993), and education about safe exercise and physical activity programs, and living arrangements (i.e. institutions, residential housing; Pitetti, 1993). Lowered self-esteem in women with disabilities often relates to less time spent participating in healthy behaviors (Nosek, 2003). Organized exercise programs specifically designed to accommodate the special needs of persons with disabilities are sometimes available, and such programs can assist individuals who are working toward improved physical health and weight loss goals. Most community colleges in California, for example, are already offering, or are in a position to offer, adapted physical education (APE) courses designed to assist people with disabilities and chronic diseases in adapting and maintaining regular exercise programs. Related courses include adapted sport, fitness, weight training, and aquatic classes.

Community college APE classes provide a low-cost opportunity for guided exercise specifically designed by educated instructors for adults with disabilities and chronic diseases. Compared to a four-year university, community colleges have fewer entrance requirements, cheaper enrollment fees, and more available sites; in California, there are 109 community college campus sites as compared to 23 state university campuses. While it would be valuable to further the study of APE among all types of 
higher education institutions, this paper will focus on APE enrollment issues at two-year community colleges. However, the lack of published primary research in this area will make it necessary to include literature from two-year, four-year, public, and private colleges. Regardless of the type of college where a student exercises, the benefits of increased physical activity are numerous and include reduction in disease risk, increased ease of activities of daily living, reduced pain, increased exercise self-efficacy, improved social support, and timely completion of undergraduate general education requirements (ACSM, 2000; Cooper, 1999; Maher, 1999; Nahas, 2003; Raveslott, 1993).

The professional literature on exercise for individuals with disabilities demonstrates that physical fitness can indeed be improved by people with physical disabilities (Beasley, 1982; Croce, 1990; Pitetti, 1993; Pollock, 1974; Stopka, 1999; Warm, 2004). There was a sprouting of college APE studies in the late 1970s and early 1980s (Crain, 1982; Duffy, 1979; MacGugan, 1979), which held promise for the field. These trailblazing studies demonstrated the various types of courses that were being designed for students with disabilities: Kl-Aikido (MacGugan), dance (Crain), and independent study in PE (Duffy). It is unfortunate, but maybe understandable knowing the financial and scheduling constraints of college instructors, that this first growth did not bloom into an expanding field of studies.

This lack of research is surprising as APE is no longer a novel idea - it is included in the curriculum at more than three quarters of the community colleges in California (APE Handbook, 2002). It is regrettable that more primary research has not been conducted, because in the 1999-2000 academic year there were 1,500,000 undergraduate students at degree-granting institutions of higher education around the nation who 
reported having a disability that affected their life. The percentage breakdown of postsecondary students with disabilities follows: $29 \%$ had an orthopedic or mobility impairment; $17 \%$ a mental illness or depression; $15 \%$ a health impairment; $12 \%$ a visual or hearing impairment; $11 \%$ a learning disability or Attention Deficit Disorder; and 15\% had some other type of disability (U.S. Department of Education, 2000). While not all college students with a disability require APE, it is obvious that tens of thousands of students throughout the United States could benefit from application of APE research.

One unique study by Craig Stewart (1988) focused on college students with disabilities. Stewart sought to describe what factors influence activity participation among disabled college students. Though his study was small and quasi-experimental with a non-validated survey tool, Stewart did find that most of the 33 respondents believed fitness was important and estimated their fitness levels to be average or below, and that slightly less than half preferred to enroll in a regular PE class. Yet, it was his subjects' extraneous comments, made almost as an aside, which stood out. Stewart commented that a few students did not realize they would be allowed in an activity class, that special classes were being offered, or that credit could be received for enrolling and participating in an adapted activity class. While the students' comments did not address the primary goal of his study, which was to examine factors affecting participation rather than factors affecting non- participation, the remarks begin to document reasons why students might avoid enrolling in special activity classes.

While a variety of APE courses are taught within the California Community Colleges District, not every student who is eligible to enroll in APE in the community colleges does so (T. Ceasar, personal communication, Spring, 2005; M. Flood, personal 
communication, Spring, 2004). Possible reasons for APE course avoidance may include: desiring inclusion in regular physical education (PE) courses; wanting to avoid association with others who are "disabled"; receiving a class waiver, excusing one from the PE requirements; lacking exercise motivation or self-efficacy; preferring to exercise on one's own; experiencing transportation and mobility difficulties; lacking information on the benefits of exercise; attending a college that does not offer APE courses; and lacking knowledge about APE offerings on one's campus. These are probable reasons for lack of enrollment, but they have yet to be validated by research.

\section{Statement of the Problem}

Even though Stewart's 1988 study was published nearly 20 years ago, it is one of the few resources addressing the APE enrollment issue. There continues to be a paucity of published studies examining why college students with disabilities do not enroll in APE courses which could help them improve their physical fitness and decrease their risk

of disease. Investigating the roles of demographics, PE and APE enrollment histories, and exercise mediators may prove helpful in designing more appropriate APE programs in institutions of higher education. Further effort should be made to investigate reasons why students avoid enrolling in APE courses as there continues to be a scarcity of general research in this area.

\section{Purpose Statement}

The proposed study will further explore the exercise profiles and reasons given for participation or avoidance of APE in community college students with disabilities. The comments made by participants in the above study by Stewart (1988) are the same type of comments previous APE students have also voiced to the researcher; "I didn't 
know adapted physical education classes existed.", "I did not think there would be anything for me to do in an adapted physical education class.", and "I did not believe it would help me feel better." (Personal communication, June, 2004) Strategies that address both reasons for APE avoidance and mediators of exercise have the potential to impact exercise participation for students with disabilities. Exercise mediators are factors that lead to a change in exercise behavior. The "exercise profile" will include several mediators of physical activity behavior that have already been established by other researchers. After conducting a meta-analysis on exercise staging, Marshall and Biddle (2001) suggest the inclusion of moderators and mediators of exercise stage transition in future studies that incorporate the transtheoretical model (TTM) of behavior change. Various fields of psychology inform the TTM to make it a multi-disciplinary theory on the progression of a behavior change. It aspires to explain the stages one progresses through when attempting to make a health behavior change. Therefore, the exercise profile will include the TTM of exercise staging, exercise self-efficacy, exercise participation expectations, and decisional balance. An elaboration on the exercise profile, including the TTM, will be included in the literature review.

The purpose of this study then is to ascertain why some eligible community college students with disabilities do not enroll in APE courses, and to determine what relationship demographics and exercise participation profile variables might have on physical activity participation. This study will begin to address this issue by using quantitative research methods to explore reasons for avoidance of enrollment in APE courses and determine the relationship between the exercise profile of San Diego County community college students with disabilities and APE enrollment patterns. More 
specifically, a survey has been designed to capture data from a population of San Diego County community college students with disabilities.

\section{Research Questions}

The survey was used to answer the following research questions:

1. What are the demographics and exercise participation profiles for students with disabilities who enroll in community colleges in San Diego County?

2. From the list provided, what are the most common reasons that students with disabilities, who have not completed an APE course, give for not participating in APE?

3. To what extent do student demographics and exercise profiles help explain why some students with disabilities enroll in APE courses and some do not?

Significance of the Study

The study was designed to assess factors that influence exercise participation in general, and adapted physical education participation, more specifically. Also, the study begins to focus on reasons why students enroll or do not enroll in community college APE courses. I have taught adapted physical education at the community college level for five years and have first-hand knowledge of why some students do not immediately enroll in adapted physical education courses, but this is generally from students who, at some point, enrolled in one or more of them. I have little knowledge of the students who never enroll, as they do not attend my classes, and, except for anecdotal comments, no study could be located which has addressed the question of APE avoidance. Quantitative research was conducted to further this knowledge bank. It is possible that the findings elucidated through this study will assist in increasing enrollment in community college 
APE courses. Also, determining the exercise profile of students with disabilities may allow teachers to better recruit students and plan appropriate retention and exercise maintenance strategies.

\section{Summary}

This chapter identified the lack of research on exercise and APE class enrollment issues in community college students with disabilities. The health problems related to a sedentary lifestyle were identified. This study employed a quantitative methodology designed to measure demographics, exercise habits, and APE and PE enrollment issues of a group that is often neglected by researchers. Currently, there is a call for more research in the area of physical activity and disability. The findings of this research begin to answer that request. Before discussing the methodology for this study a brief literature review of three areas related to APE participation in the community college is provided. 
Chapter 2

Literature Review

To set the stage for a study on adapted physical education enrollment and exercise participation issues, this section reviews relevant literature. Specifically, the following bodies of literature will be summarized: (a) APE in the California Community College system; (b) rates and benefits of exercise; and (c) the transtheoretical model of behavior change.

Adapted Physical Education in the California Community Colleges History of the California Community College System

The California community college system has developed into the largest system of higher education in the world; it is organized into 109 colleges in 72 districts and serves more than 2.9 million students, including more than 85,000 students with a verified disability (California Community College Chancellor's Office, 2004). What began with the passage of a state law in 1907 authorizing local high schools to establish post-secondary courses, received a needed boost in 1960 with the Master Plan for Higher Education. A large surge of students born after World War II inundated the colleges and universities in the 1960s (Rawls, 2002). California greatly expanded its public education system in response to this insurgence, known as Tidal Wave I (Rawls).

The Master Plan for Higher Education was adopted by the legislature to prepare for this insurgence (Rawls, 2002). The Master Plan included the three main segments of higher education in California: the State University System, the University of California system, and the two-year college system. The role of two-year community colleges has 
been to prepare students to transfer to the State University and University of California systems, complete associate's degrees, or train for vocational or technical programs.

While the California higher educational system was improving college access for the men and women of California in the 1960s and 1970s, legislation was being designed to greatly improve access to higher education and recreational pursuits for those with disabilities. For the first time, federal legislation mandated the termination of architectural barriers in publicly funded buildings and facilities (Lepore, 1998). It is appropriate to briefly review a few of these laws.

\section{The Role of Legislation}

In effort to reduce barriers to public education for people with disabilities, it was necessary to establish several legislative acts. Public Law 93-122, The Rehabilitation Act of 1973 , section 504, mandates that all programs and facilities receiving federal monies must be made accessible. Local and state governments subsidized renovation and construction of new facilities to remove barriers to those with physical disabilities. Structural updates were made to universities, recreational facilities, pools, bathrooms, parking spaces, and government buildings. In the 1970s, Public Law 94-142 (PL 94142), The Education for All Handicapped Children Act, mandated a free and appropriate public education in the least restrictive environment for all students. Later, PL 94-142 was amended to include students from three to twenty-one years of age.

Access was improved by the implementation of these laws, but discrimination continued to occur (Lepore, 1998). Therefore, Public Law 101-336, The Americans with Disabilities Act (ADA), was passed in 1990. This law made it illegal for anyone who owns, leases, or operates a public place to discriminate based on disability. People with 
disabilities were to receive full and equal access and enjoyment of facilities, services and goods (Lepore). With the passage of these public laws in the late twentieth century, the privileges of all individuals to participate in educational and recreational pursuits in publicly funded arenas became the rights of those with disabilities as well. Unfortunately, people with disabilities continue to report limited access to physical activity arenas (Guthrie, 1999).

\section{Meeting the Physical Education Requirement}

As more students with disabilities enrolled in college, obstacles in meeting their academic needs arose. Finding a way for these students to meet the PE requirement was one such challenge. Students working toward an associate's degree or completion of general education classes in preparation for transfer to a four-year institution are often required to fulfill a physical education requirement. Though the California Community Colleges do not have a state-mandated PE requirement, many schools choose to independently enforce the requirement. For instance, all of the community colleges in San Diego County have instituted a requirement of at least one physical activity class as part of an associate's degree. Acceptable courses include activity, fitness, aquatic, combative, intercollegiate sport, and adapted classes. APE course offerings are one way to help students with disabilities meet their PE requirement. Other options include mainstreaming in regular physical education or waiving the PE requirement; but neither one of these options is consistently appropriate or in the best interest of every student. To assist colleges in addressing complicated APE program issues and designing appropriate APE courses, a handbook was designed. 
Disabled Student Programs and Services of the California Community College Chancellor's Office sponsored the development of the Adapted Physical Education Handbook (2002). Through extensive surveys, site visits, and internet and literature searches the task force composed a handbook reflecting the status of APE in the California community colleges. The APE Handbook contains guidelines and regulations on most aspects of community college APE. It defines APE as intended for adults whose mental and physical limitations prohibit them from fully participating in non-adapted physical education (APE Handbook). The purpose of APE is to design safe and appropriate learning environments where a person with a disability can learn physical education concepts and improve physical skills (APE Handbook).

According to the APE Handbook (2002), 84 (78\%) of the 108 community colleges (the 109th college has since been admitted to the system) offered adapted physical education classes. Twenty-one colleges did not offer APE classes, and 3 were planning on offering them in the near future. More than 7,456 students were enrolled in APE courses at the 67 colleges completing the survey (APE Handbook). A student with a disability may either enroll in a non-adapted physical education class while expecting reasonable accommodations to be made or, if available, may enroll in an adapted physical education class designed to meet his or her unique needs and abilities. Any student with a verified mental or physical disability would qualify for APE and be able to enroll in a class which is smaller than regular PE and staffed by instructors educated in disability and chronic disease issues.

Unfortunately, even with these types of accessibility issues addressed, there may be other barriers students must overcome before participating in APE - barriers not yet 
documented. Though these classes are available, they are not always utilized to their fullest extent. Using data from the California Community College website (www.ccco.edu) and the APE Handbook (2002), one can calculate that in the 2000-2001 academic year, there were almost 60,000 students with disabilities (not including those with learning disabilities as most, it is assumed, may prefer regular PE) enrolled in California community colleges. Approximately 7,500 students were enrolled in APE courses (APE Handbook). Therefore, only about $12 \%$ of students eligible to take APE courses actually enrolled in them. Even though approximately $25 \%$ of the community colleges in California did not offer APE courses during the 2000-2001 school year and some colleges may not institute a PE requirement, there must be other reasons for this lack of enrollment that have yet to be empirically identified. First, it is necessary to determine if this enrollment pattern is common and if so, what barriers exist to APE course enrollment. Then, recognized barriers may be altered to promote APE enrollment and increased physical activity for more eligible students. Increasing the physical activity level for all individuals is a national goal; the community colleges can strengthen their efforts in this endeavor.

\section{Physical Activity Issues}

\section{Rates of Physical Activity}

People with disabilities are less likely to engage in moderate physical activity three times per week and are more likely to be obese (CDCP, 2004; Weil, 2002). Healthy People 2010 (HP 2010) is tracking the trends of low physical activity patterns for Americans and setting new activity goals. Within Healthy People 2010 there are 10 leading Health Indicators that represent the top 10 health issues in America, including: 
health care access, immunization, obesity, physical activity, tobacco use, mental health, substance use, sexual behavior, injury, and environmental quality. Baseline data gathered in 1997 determined that only $12 \%$ of adults with disabilities are physically active for thirty minutes per day, five days per week, as compared to $16 \%$ of adults without disabilities. Twenty-three percent of adults with disabilities are physically active 20 minutes per day, three days per week, as compared to $33 \%$ of adults without disabilities (CDCP). Taken together, these statistics show that the participation rate for adults with disabilities is lower than that for the whole adult population. Considering that a college environment may be a microcosm of society, this lack of physical activity in the general population may be caused by the same factors that relate to the predicted sedentary lifestyle patterns of college students with disabilities. The proposed research will determine what factors relate to sedentary patterns in students with disabilities and compare these new findings to previously published studies on non-disabled college students.

As in other disciplines, college students have been popular research candidates for the study of exercise science. The exercise rates of college students have been studied and found lacking at below 50\% (Douglas, 1997; Pinto, 1995; Guyrcsik, 2004). Results from the 1995 National College Health Risk Behavior Survey demonstrate that $37.6 \%$ of college students reported they had participated in vigorous physical activity on at least 3 of the preceding 7 days and $19.5 \%$ reported participating in moderate activity on 5 or more of the preceding days (Douglas). Forty-seven percent of non-disabled female freshmen failed to meet national recommendations for vigorous physical activity, defined as twenty minutes of continuous vigorous activity on three days per week (Gyurcsik). 
Additionally, Pinto determined that $46 \%$ of college students were inactive or active on an irregular basis. In one study of college seniors, approximately $53 \%$ of women and $35 \%$ of men were inactive (Sallis, 1999), illustrating significant gender differences. While the activity level of disabled college students could not be established, it is expected to be substantially lower than that of their non-disabled peers, which does not bode well as less than half of non-disabled college students meet guidelines for physical activity. The good news is that after college graduation many healthy behaviors are more frequently practiced by those with a bachelor's degree than those with less than a high school diploma, a high school diploma, or some college.

As education increases, individuals are more likely to exercise or play sports regularly and are less likely to be twenty percent or more above desirable weight (Postsecondary Education Opportunity, 1999). While some of these correlates may be related to benefits from higher paying employment, other correlates may be related to having the ability to make more informed decisions. The ability to access reliable health information, consider options, and make healthy choices may positively influence the health-related behaviors made by college graduates. Also, alumni from colleges with more stringent physical education requirements demonstrate more positive exercise behaviors and attitudes than graduates from colleges with less demanding requirements (Adams, 1992). Maintaining high expectations for all students increases the quality of higher education; requirements should not be lowered for students with disabilities, but adapted for them, in hope that they will be able to use their health literacy and physical activity skills to practice healthful behaviors after graduation. While studies of exercise for college students with disabilities are lacking, research journals include numerous 
examples of safe, progressive exercise interventions that improve fitness levels of people with disabilities.

Previous investigations have illustrated that the physical activity levels of people with disabilities can be increased through intervention. As an example: adults with spinal cord injury participated in a pilot study aimed at increasing the participants' lifestyle physical activity. Six weeks after a short intervention $60 \%$ of the adults were more active (Warms, 2004). Therefore, even a short intervention may promote physical activity levels that meet the HP 2010 target of three to five exercise sessions per week for at least $30 \%$ of adults with disabilities. ${ }^{1}$ College quarters and semesters are two to three times the length of the intervention described by Warms, possibly providing college instructors a more extensive opportunity to promote physical activity as a healthy lifestyle component.

Clearly, a faction of non-disabled university students will voluntarily enroll in sport, fitness, and health classes (Armstrong, 2002). Ninety-nine percent of the 2,181 students who responded to a survey admitted to having taken a prior sport, fitness, or health class. The most commonly reported reasons for enrollment were desire to improve skills and increase knowledge of health and fitness. Students rated the performance of the instructor to be the most important component of course delivery quality (Armstrong, 2002). Hildebrand and Johnson (2001) determined that "enjoyment" was the number one reason college students enrolled in a college physical activity class. Students were more likely to enroll in physical activity classes if they were already proficient at the skills

\footnotetext{
${ }^{1}$ Center's for Disease Control \& Prevention, http://www.cdc.gov/ncbddd/dh/hplhidata.htm retrieved on $12 / 13 / 04$.
} 
used in the courses and if they experienced high school PE classes that that were of high quality.

Interestingly, a preliminary study recently completed in preparation for this proposed dissertation concluded that some students with disabilities will re-enroll in fitness courses and decide to participate in physical activity for reasons similar to their non-disabled peers as cited by Armstrong (2002) - to improve their health and fitness. There may be other similarities between college students with disabilities and their nondisabled counterparts; for example, a knowledgeable and motivating instructor who can assist with exercise promotion and maintenance is likely desired by both groups. Addressing the benefits of physical activity and self-efficacy issues (Cardinal, 2004; Kosma, 2002, 2004) in the exercise class may promote increased exercise adherence. Debates continue as to whether activity-based or conceptually-based physical education classes contribute more to alumni's lifetime fitness habits (Adams, 1995). The studies mentioned in this section were cross-sectional and short-term designs, because highquality longitudinal studies that examine the long-term effectiveness of college PE programs, as measured by physical activity rates and health status, are nearly non-existent (Corbin, 2002).

\section{Benefits of Physical Activity}

Many studies illustrate the benefits of exercise for people with disabilities and chronic disease. Either type of intervention, physical activity counseling or structured exercise programs, can increase physical activity and improve cardiovascular disease risk in sedentary women and men after six months. Other training programs have demonstrated increases in cardiovascular endurance (Croce, 1990; Montgomery, 1988; 
Rimmer, 2004), muscular endurance (Montgomery; Rimmer), and muscular strength (Rimmer; Suomi, 1995) in adults with mental impairments. Endurance can be increased in individuals with lower limb disabilities by use of upper body ergometry (Pollock, 1974). Subjective well-being can be improved by reduced stress (Ginis, 2000), depression (Ginis), and anxiety (Katula, 1999), or increased feelings of personal empowerment (Blince, 1999) following exercise or sport participation. One metaanalysis examined the effects of exercise on physical fitness components in individuals with intellectual impairments (Chanias, 1998). Cardiovascular endurance, muscular strength, muscular endurance, and flexibility are four components of a comprehensive fitness plan that have been improved with exercise training in differing populations of people with disabilities (Chanias).

For research purposes, many of the studies just mentioned tailored interventions to specific disability categories, but Ravesloot, Seekins, and Walsh (1997) and Wilber et al. (2002) do not believe this segregation is necessary for health and wellness interventions. Health promotion interventions designed for the mainstream population could be used with little or no modification (Ravesloot, 1997) for a heterogeneous group of students with disabilities. Including APE courses within a larger health promotion campaign is a promising strategy; the courses should be based on a comprehensive fitness plan as outlined by the ACSM (2000). For this reason, a student enrolled in APE could be expected to attain one or more of these fitness benefits if actively participating in an appropriate, well-designed exercise program that promotes a healthy active lifestyle. 


\section{Promoting a Behavior Change}

As stated earlier, enrollment in APE courses is one opportunity for college students with disabilities to increase their level of exercise participation. However, more information is needed to better understand the potentially unique exercise profiles of these students. The Transtheoretical Model (TTM) may be helpful in understanding stages of exercise behavior and mediators of exercise participation in students with disabilities, although it has not yet been applied to a disabled student population. Researchers are using the TTM of behavior change to study the process of beginning and maintaining an exercise program in healthy adults (Buckworth, 2001; Cardinal, 1995a; Cardinal, 1997b; Marcus, 1992a; Marcus, 1992b; Marcus, 2003; Plotnikoff, 2001; Prochaska, 1997), in women (Cox, 2003), in college students (Buckworth; Sallis, 1999a, Sallis, 1999b), and in adults with disabilities (Cardinal, 2004; Kosma, 2002; Kosma, 2004). A review of the TTM will be followed with a discussion on how it can be used to promote exercise in non-disabled and disabled populations.

The Transtheoretical Model of Health Behavior Change.

The transtheoretical model was first developed by Prochaska and DiClimente (1983) to examine the stages of change people progress through as they attempt to become a non-smoker. As its name suggests, this model is a blend of psychotherapy and behavior change theories, including the consciousness raising theory from Freud, contingency management from Skinner, and helping relationships from Roger (Prochaska, 1997). A growing number of researchers are using the TTM (Marshall, 2001); because of increasing popularity, this model has evolved into a multidisciplinary theoretical model describing the stages one moves forward and backward through when 
trying to make any one of a number of positive health changes, such as stopping drug abuse, making dietary changes, or increasing one's physical activity.

The TTM posits the five stages through which people tend to progress with varying degrees of readiness or involvement as a behavior change is made. The fives stages are: a) precontemplation (i.e., the person is not thinking about making a behavior change); b) contemplation (i.e., the person is thinking about making a behavior change within the next six months); c) preparation (i.e., the person has decided to make or is in the process of making a behavior change); d) action (i.e., the person has overtly changed a behavior, but for less than six months); and e) maintenance (i.e., the person has practiced a behavior change for at least six months) (Cardinal, 1997b). Individuals move forward, and backward, through these stages as they attempt to change a behavior. It has been a long-standing belief that baseline staging of participants' exercise habits can lead to stage-matched interventions (Buckworth, 2001) which help participants move forward to a more advanced stage and assist "maintainers" in continued exercise participation. The stage of exercise five-item scale was previously demonstrated to appropriately classify subjects by stage as compared to physiological testing: exercise energy expenditure, physical activity energy expenditure, and physical exercise capacity (Cardinal, 1997a). Dishman, Washburn, and Schoeller (2001) describe the difficulties in directly measuring physical activity and list three worthy self-reporting physical activity measures. Unfortunately, two are interviewer-administered and the other is not appropriate for people with disabilities. Therefore, the TTM staging tool can be of benefit when direct physiological measurements and interview-guided or self-reported tools are not suitable. 
Using the TTM can allow instructors and researchers to classify participants into exercise stages and tailor cognitive and behavioral interventions to fit each individual's needs. In fact, research has shown improvements in exercise program recruitment and stage progression when using stage-matched intervention programs (Prochaska, 1997). In particular, students in the preparation phase have a greater chance of moving to a higher stage and increasing their self-concept when given stage-matched tools (Van Vorst, 2002). Besides the stages of change, there are other components of the TTM including constructs of behavior change, such as decisional balance and two types of efficacy (Cardinal, 2004; Marshall, 2001).

\section{Decisional Balance}

Decisional balance is based on a comparison of the perceived positive benefits (pros) and negative consequences (cons) of engaging in a new behavior (Marcus, 1992a). People in the precontemplation stage tend to present a decisional balance favoring the cons while those in the action and maintenance stages have a decisional balance favoring the pros. Those in the contemplation stage tend to fall in the middle. Recognizing one's decisional balance may be important in predicting stage progressions (Marcus).

Included in the negative consequences on the decisional balance scale are barriers to exercise. The impact that barriers have had on keeping people with disabilities from participating in activities that the general population has had access to cannot be ignored. A special section recognizing the barriers to exercise participation must be included.

Barriers. Both internal and external barriers to starting and maintaining exercise programs are well documented. For example, Odette et al. (2003) examined barriers to participation in wellness activities for Canadian women with physical disabilities. They 
determined that the challenges perceived by women with disabilities included both structural and individual barriers. Structural barriers, including the physical environment, and communicative and economic obstacles, were more commonly detected than individual barriers, such as physical capacities. Physical capacities were mentioned and categorized as complaints of limited energy, fatigue, and joint movement.

Non-disabled college students also report barriers including lack of motivation, injury, fatigue, illness, social commitments, training partners (or lack thereof), and feelings of intimidation by an unfamiliar social environment (Gyurcsik, 2004). Institutional barriers included conflicts with open gym time, commitments at work, time constraints due to school workload, and difficulties dealing with the stress of college life. Community and environmental barriers included lack of sports teams to join, lack of transportation, weather, and lack of facilities (Gyurcsik). Students' perceived barriers of effort, time, and obstacles have been shown to predict physical activity in a PE class and during leisure time (Steinhardt, 1989).

While the research by Gyurcsik, Bray, and Brittain (2004) and Steinhardt and Dishman (1989) highlights barriers for non-disabled adults, Kinne, Patrick, and Maher (1999) did not find that perceived barriers correlated with exercise participation among people with mobility impairments. Demographics, environmental barriers, and disabilityrelated barriers failed to differentiate between those who did and those who did not exercise (Kinne). The difference between perceived barriers to physical activity for adults with and without disabilities is unexpected and may be related to study design or measurement tools. Intuitively, it continues to be important to determine how perceived 
barriers to physical activity participation affect exercise habits of college students with disabilities.

Efficacy of Exercise

Exercise efficacy is another mediator of exercise behavior. Resnick, Zimmerman, Orwig, Furstenberg, and Magaziner (2000) describes two theories of efficacy: self-efficacy expectations and outcome expectations. Self-efficacy expectations are the beliefs that one has confidence in one's ability to perform a particular behavior. Outcome expectations are the beliefs that participating in a specific behavior will lead to a desired outcome (Resnick, 2000). The use of both of these measures is described in the following section.

Self-efficacy expectations. A strong indicator of healthy behavior adoption (Cox, 2003), self-efficacy is also related to exercise adoption and maintenance among college students (Gyurcsik, 2004; Sullum, 2000) and adults (Kinne, 1999; Marcus, 1992c; McCauley, 1992; McCauley, 2003; Sallis, 1989). Self-efficacy may improve in a linear fashion (Cardinal, 2004) as one progress through the stages of change for exercise or improvements in selfefficacy may be dependent on stage subgroups (Cox). In Cox's study of sedentary women, self-efficacy in overcoming barriers only improved in those women who progressed from the contemplation to the action stage (2003). McAuley, Jerome, Marquez, Elavsky, and Blissmer (2003) have demonstrated that self-efficacy does not remain constant, but fluctuates over the course of a six-month exercise intervention. At the end of the program, rates of self-efficacy were demonstrated to be influenced by affective, behavioral, and social factors (McAuley, 2003). Comparatively, qualitative data highlighted the important social, psychological, and physical improvements made after a ten-week exercise intervention in adults with disabilities (Maher, 1999). If a teacher can address these different issues within her class, she may have a 
substantial impact on the exercise adherence of her students not only during the class session, but after its completion; she may use the inherent social nature of her class to increase selfefficacy.

By design, APE classes are not one-on-one training sessions; they are made up of groups of students. Classes can be structured to include a group exercise component; for example, stretching can be done in a circle. Group activities will increase the social aspect of the class and add opportunities for students to get to know and offer support to each other. Students are able to encourage each other and model healthy behaviors which have the possibility of increasing self-efficacy, self-esteem, class attendance, and exercise adherence. Group interventions have been promoted (Deardon, 2002) and demonstrated to improve health and well-being for women with disabilities and chronic illness (Hughes, 2003). The opportunities for social networking inside and outside of class may be beneficial as women with disabilities who feel socially isolated are less likely to participate in health promoting behaviors (Nosek, 2002). Nahas, Goldfine and Collins (2003) wrote an overview examining factors that influence physical activity adoption and/or maintenance in high school and college students. Self-efficacy was shown to be related to success in performing regular physical exercise (Nahas, 2003).

Outcome Expectations. The second type of self-efficacy, outcome expectations for exercise (OEE), is a measure based on Bandura's theory on self-efficacy. People with greater outcome expectations for exercise are more likely to begin and maintain an exercise program (Marcus, 2003; Resnick, 2000; Steinhardt, 1989). Therefore, the OEE scale can be used to help predict exercise behavior or to tailor an intervention to an individual. The overall score of 
the respondent's answers can be used as a predictor of future behavior or the response of an individual item can allow a specific intervention in an area in which the respondent scored low.

Assessing the relationship between exercise efficacy and physical education participation is important. Techniques for increasing exercise self-efficacy and outcome expectations could be implemented into the curriculum to create classes better suited to students with disabilities. Saracoglu, Minden, and Wilchesky (1989) compared a sample of students with learning disabilities to a control group of non-learning-disabled students. Selfesteem was positively correlated with general self-efficacy in both groups of university students. Increasing exercise efficacy, both self-efficacy and outcome expectations, may promote physical activity both in the educational and home environments. Promoting lifelong activity has long been a primary goal of physical educators (Corbin, 2002a).

\section{Summary}

Community college adapted physical education classes provide an opportunity for adults with disabilities to enroll in high-quality, low-cost physical activity classes. Humanity and public laws support the rights of these students to have educational opportunities equal to those of their non-disabled peers. Encouraging more students with disabilities to recognize the benefits of regular exercise participation and to enroll in adapted or regular physical education programs holds the potential promise of improvements in health and reductions in disease. Using components of the TTM to predict future behavior may allow physical educators to better recruit students with disabilities and motivate them to exercise.

Future research should examine ways that higher education institutions can promote physical activity for students with disabilities. More frequent use of physical 
activity as a dependent measure in the research of APE was suggested by Reid (2000) as a way to strongly impact the field. Colleges and universities would then be able to apply this knowledge to reduce barriers and implement techniques that increase exercise selfefficacy and participation among individuals with disability and chronic disease. The authors of a Department of Veterans Affairs Report have even recommended that future research address seven areas of physical activity and health among persons with disabilities (Cooper, 1999). One specific area that future researchers should focus on is determining the factors that affect physical activity motivation and adherence to exercise (Morgan, 2001). Special attention should be given to access issues within the organizations and facilities that promote physical activity and exercise opportunities for people with disabilities (Cooper).

Previous studies and monies have focused on preventing disease in healthy individuals (Dunn, 1997) and rehabilitating persons with disabilities and chronic diseases. The development of health promotion models that specifically address the needs of individuals with disabilities is lacking (Ravesloot, 1998). The slow increase in the visibility of health promotion programs for people with disabilities demonstrates how comprehensive health promotion interventions, including exercise and nutrition components, can decrease health care costs and improve quality of life (Ravesloot, 2005). Future research should focus on health promotion, including reduction of risk factors of secondary disease in those with disabilities (Rimmer, 1999) and the effectiveness of physical education programs (Corbin, 2002b).

The proposed study will be designed to assess exercise profiles and factors that influence enrollment in or avoidance of adapted physical education classes among 
community college students with disabilities. Once these issues are addressed, college faculty and administrators can begin to examine ways to improve the efficacy of health promotion opportunities on campus, such as those found in community college APE programs. 


\section{Chapter 3}

\section{Methodology}

In this chapter, the research design and methodology for gathering information about the demographics, exercise profiles and adapted physical education enrollment patterns of community college students with disabilities will be discussed. Specifically, a description of the sites, respondents, survey tool, instrument administration, and statistical analysis are included.

Sites

This study employed a convenience sample made up of the eight community colleges located in San Diego County, an easily accessible part of the state for the researcher. Even though the schools of San Diego County were selected because of accessibility, this choice was a good one, because it allowed data to be gathered from the entire county population. This population included a total of eight community colleges located in five districts.

Including colleges in one region of California helped to ensure that the data collection was manageable and financially feasible, yet it still allowed for the inclusion of inner-city, suburban, small, and large colleges. Also, it allowed for a heterogeneous sampling of schools with various types of APE programs. The schools in the study population included established APE programs, transitional programs, and no APE courses or programs at all. (In schools with no programs, students with disabilities sometimes have the option of taking APE at a nearby community college.) It is very likely, in other words, that this group of colleges exhibited the range of APE offerings characteristic of the California community colleges population (APE Handbook, 2002). 
The study would not have been possible without support from the Director of Disabled Student Programs and Services (DSPS) on each campus; $100 \%$ of the DSPS Directors agreed to allow their students to participate in the study. Permission to conduct this research study and access students was requested from the Director of DSPS at each of the eight participating colleges and from any other school administrator they requested. By attending the DSPS Regional 10 Coordinators' Meeting on February 10, 2006 , the researcher of the proposed study was introduced to personnel from each of the college sites. The purpose of this study and data collection methods were discussed. After IRB approval was given, the next step was to send each DSPS Director a letter, followed-up with a phone call, asking the Director to support data collection and confidentiality issues as discussed in the Data Collection section. In the letter and during the phone calls, an organized plan was presented detailing how the bulk of the work was to be performed by the primary researcher, using the school's resources as little as possible. An offer was made to return to a DSPS Regional 10 Coordinators' Meeting to present the study's findings after the data is collected and analyzed. The letter is included in Appendix A.

\section{Respondents}

The study population included all students at the eight selected institutions who were registered with DSPS and whose primary disability classification was one of the following: Mobility Impairment, Visual Impairment, or Other Disability. The Other Disability category includes people with chronic diseases, such as heart disease, diabetes, or arthritis, and disabilities, such as Attention Deficit Hyperactivity Disorder, that do not fit into other categories. One exception was made to this; DSPS staff at College A 
requested that their students who were classified as having an Acquired Brain Injury also be included. Their reasoning was that these are students who frequently register in APE courses and they should be invited to participate in the research. While this category of students was considered by the researcher, this group was not originally included due to memory problems which are a common lingering side effect of a brain injury.

Nevertheless, the request from College A was honored. Consequently, approximately 1,200 students made up the study population in the proposed study.

Data Collection Methods

Instrument design. Respondents received a letter from the primary researcher explaining they were chosen to participate in a study on APE participation, exercise beliefs, and demographics of community college students with disabilities. The letter and survey are included in Appendices B and C. The survey consisted of approximately 49 questions. Two questions had a skip pattern, three questions were open-ended, and the remainder included questions with Likert-type scales or multiple choice menus. Descriptions for the content of the survey questions are as follows: one asked for participation consent; six inquired into past participation and two inquired into future expected participation in college level APE and PE classes; six are demographic questions inquiring about disability type, age at onset of disability, college semesters completed, age, gender, and race/ethnicity; and 32 Likert-type questions or multiple choice menus were related to exercise. Also, the open-ended questions inquired into the respondents' experience with the survey, reasons for avoiding APE, and thoughts on ways to make APE more accessible. 
Four scales made up the majority of the survey and were based on constructs of the Transtheoretical Model that examine exercise mediators, factors believed to influence exercise behavior. The scales rated four distinct areas, (a) one stage of exercise scale, (b) five exercise self-efficacy questions, (c) ten outcome expectations of exercise questions, and (d) sixteen perceived benefits of and barriers to exercise questions. A more extensive discussion of each of the scales is provided below.

Stage of exercise model. The stage of exercise is determined using Cardinal's (1995a, 1997a) five-item ordered-categorical scale ("I presently exercise on a regular basis, but I have only begun doing so within the past 6 months"). The stage of exercise scale has been demonstrated to have an internal consistency of .76 and to differentiate between subjects at different stages, $\mathrm{F}(4,369)=36.57, \mathrm{P}<.001$ (Marcus, 1992c). Subjects in different stages also significantly differed in physiological measurements; indicating that the scale was sensitive enough to differentiate between fitness levels between subjects in each of the stages of exercise (Cardinal, 1995a). The stage of exercise measure was demonstrated to be reliable when tested over a two week period $($ Kappa $=.78$; Marcus, 1992c). Since Kappa values over .75 show a strong relationship (Marcus, 1992c), the stage of exercise score is not expected to change over a short period of time unless an intervention occurs. In addition, test-retest reliability was determined by others to be adequate (Cardinal, 1995a and $b ; \mathrm{r}_{\mathrm{s}}=.93$ to 1.00 ).

Exercise self-efficacy. The self-efficacy scale for exercise measures the student's confidence in participating in regular exercise under five situations: when tired; when in a bad mood; when feeling time constraints; when it is raining; and when on vacation. Total scores on the five-item self-efficacy scale were able to differentiate subjects at different 
stages of exercise, $\mathrm{F}(4,369)=36.57, \mathrm{p}<.001$ (Marcus, 1992c). Approximately $28 \%$ of the variance in stage of exercise was explained by exercise self-efficacy. Generally, those in the lower stages of exercise, score lower on the exercise self-efficacy scale while those in the higher stages of change, score higher (Cardinal, 2004). This measure has been demonstrated to have a high internal consistency, $\alpha=.76-.82$ (Cardinal, 2004; Kosma, 2004; Marcus, 1992). Test-retest reliability was measured over a two-week period and determined to be .90 (Marcus, 1992c). A Likert-type scale will be used to measure agreement to five statements measuring exercise self-efficacy.

Outcome expectations for exercise. Nine questions measuring expected physical and mental benefits of exercise are included in the Outcome Expectations for Exercise (OEE) Scale (Marcus, 2003, Resnick, 2000). A recent investigation on the use of the OEE scale for older adults determined the internal consistency was .89. The relationship between $\mathrm{OEE}$ and exercise behavior was significant $(\mathrm{F}=31.3, \mathrm{p}<.05)$. The relationship between OEE and self-efficacy expectations was also supported ( $r=.66$; Resnick, 2000). Resnick (2000) determined one of the statements (Item 9: "Exercise helps to strengthen my bones") to have lower reliability than the other eight statements $\left(R^{2}=.32\right)$. This $R^{2}$ value indicates that only $32 \%$ of the variation in the question on bone strengthening was explained by the model. Also, confirmatory factor analysis demonstrated that removing item 9, statistically improved the fit of the model. Regardless of these findings, the statement on bone health was kept in the current study to determine if Resnick's finding are duplicated, per the suggestion of Resnick, and if the student population rates this question differently than the older adult population studied by Resnick. In addition, a tenth question was added to the scale to measure the expectations of body weight 
changes. The OEE survey tool utilized a Likert-type scale to measure respondents' agreement to 10 statements such as "Exercise makes me feel better physically" and "Exercise makes my mood better in general."

Decisional balance. A Decisional Balance Scale was used to measure the perceived advantages and disadvantages of exercise. The actual score was determined by subtracting the respondents' total score of disadvantages from their total score of advantages (i.e., pros - cons) (Marcus, 2003). Data analysis has allowed researchers to minimize the number of questions included in a decisional balance scale. An initial pool included 75 statements, but this has commonly been reduced to either a sixteen-item (Marcus, 1992a; Marcus, 2003) or ten-item (Kosma, 2004, Plotnikoff, 2001) scale. Plotnikoff (2001) conducted multiple analyses of the shorter measure and found it to be a robust scale applicable for use as an exercise mediator in many arenas, but the longer scale designed by Marcus, Rakowski, and Rossi (1992a) may be more appropriate for the current study as it includes statements such as "It would be easier for me to perform routine physical tasks if I were regularly physically active". Statements such as this may improve the fit of the model and explain more of the variance in outcomes when used with a population that is disabled. Therefore, instead of using the ten-item scale, the sixteenitem scale was included in the survey.

Pre-testing Procedures

Pre-testing and piloting was conducted following procedures outlined by Bradburn, Seymour, and Wansink (2004). A pre-test was conducted by providing the survey questionnaire to four students with disabilities and eight colleagues. The individuals who conducted the pre-test were asked to a) complete the questionnaire, b) inform me of items that were confusing, and c) discuss if the survey included areas that 
could be misinterpreted. Also, they were asked to be critical of the content and structure and to admit if they found any offending statements.

A pilot test (face validity assessment) was conducted by providing the survey website to three college students with disabilities who were not in the study population. After the questionnaire was completed, discussions were held with the respondents to determine whether they had difficulties in interpreting and completing the survey. They were asked for general comments and feedback on ease of use and clarity of questions. The instrument is included in Appendix C.

\section{Instrument Administration}

Some college sites asked to approve the survey invitation letter prior to it being sent out to the study population. The letter introduced the primary investigator, affirmed the school's support for the research, and encouraged the student's participation. In order to reduce the DSPS Director's time commitment, I drafted a form letter and made changes based on the needs of the school and feedback from the director. Only modest tailoring was needed; for example, College A requested that the letter include the specific room numbers of computer labs on campus where students could complete the survey. The final draft of the letter, personalized for each school and signed by the primary investigator, was mailed to each subject. A copy of this letter is included in Appendix B.

Also, I asked each DSPS director to assign a knowledgeable staff person to print mailing labels for all students fitting the inclusion criteria. A total of three sets of mailings were prepared at each school. Depending on the preference of the school, either someone in the office or I labeled all mailings. My contact person in the DSPS office made sure each mailing was picked up by college postal services. Lastly, the first and 
second student letters included a date I would be available on campus to assist anyone, who scheduled an appointment, with the survey. A private room for conducting interview surveys was reserved for this purpose.

\section{Instrument Collection}

The survey was designed to be used as an internet or mail survey. Students were asked to go to the Surveymonkey website and complete the survey. The survey cover letter included directions to the website and instructions for completing the survey. A different website address was used for each college to automatically disaggregate the data by school. If an alternate form (i.e., a hard copy, a copy with large print) of the survey was requested then it was mailed to the respondent along with a postage paid return envelope. The Surveymonkey website provided an excellent alternative to the traditional mail survey format as it saved printing, postage, and data inputting costs. The privacy policy of Surveymonkey stated that they would not use the data for their own purposes and that the collected data would be kept private and confidential. Servers were kept in locked cages with an entry pass card and biometric recognition required for entry. Digital surveillance equipment was used. An extra fee was paid to Surveymonkey to ensure that the survey link and survey pages were encrypted during transmission. Once the survey was completed and the data withdrawn, the survey data was deleted from the surveymonkey.com website. Only the primary researcher and her university adviser had access to the exported data which was downloaded onto her password-protected computer.

Guidelines for survey collection by mail have been outlined by Salant and Dillman (1994) and modified to meet the requirements of an internet survey protocol 
where students are invited by a mailed letter to respond. Originally, a buoyant attempt was made, keeping in mind Salant and Dillmans's guidelines, with hopes of receiving at least a 50 percent response rate from each school. The forth mailing recommended by Salant and Dillman was cancelled due to low response rates coupled with high printing and mailing expenses. Student letters were sent as follows:

1. To all members of the population - a personalized letter informing students that as a registered DSPS student they are invited to participate in an online survey. Instructions, including survey website address, were included.

2. Two weeks later, a letter thanking those who have responded and requesting a response from those who have not was mailed to the whole population.

3. Four weeks after the first letter was sent a third and final request was mailed to the whole population, thanking those who had responded and asking those who had not responded to please complete the survey before it closed. The letter included encouragement to contact the researcher if assistance or an alternate survey format was desired.

4. In addition, offers were made to assist students by phone and email, or by scheduling an appointment with the researcher. This appointment was schedule approximately five weeks after the date of the first letter. Only one student who made an appointment attended the meeting to receive assistance with his survey. Two others made appointments, but did not show at the scheduled time.

\section{Data Analysis Procedures}

Respondents' answers to survey questions were entered into SPSS, version 11.5, and analyzed through the techniques of frequencies, t-tests, and logistic and multiple 
regression analyses. The Likert-formatted questions used to form the various scales were analyzed using factor analysis. Multiple regression analysis was used to assess the effect of stage of exercise, self-efficacy, decision balance, outcome expectations, and demographics on the number of previous APE and PE classes taken and the four exercise scales. Logistic regression analysis was used to estimate predictors of APE enrollment.

RQ1: What are the demographics and exercise participation profiles for students with disabilities who enroll in community colleges in San Diego County?

The data was analyzed using descriptive statistics to produce means and standard deviations. Frequencies and percentages for the close-ended demographic questions are reported. While the original expectation was to have large enough data pools from each college allowing a cross-case analysis to be performed, the reality was that a combined data pool would be necessary for statistical comparisons.

RQ2: From the list provided, what are the three most common reasons that students with disabilities, who have not completed an APE course, give for not participating in APE?

The data were analyzed using frequencies and percentages.

RQ3: To what extent do student demographics and exercise profile components help explain why some students with disabilities enroll in physical education courses and some do not?

Regression Analysis was used to determine the extent that the independent variables -- student demographics and exercise profile components -- related to APE and PE enrollment. The independent variables were chosen for the multiple regression models for their potential impact upon physical education enrollment. To create the 
models, APE and PE enrollment histories and information from the demographic data were coded for statistical analysis. Scores from the stage of exercise, self-efficacy, outcome expectations of exercise, and decisional balance scales were determined by the processes outlined by Marcus and Forsyth (2003). All the data were analyzed using the statistical package for the social sciences (SPSS, version 11.5). To code the demographic information, age, gender, and disability category were represented by dummy variables. To address the number of semesters completed, students were asked to choose the following category that best represents the number of college semesters completed: $0-2$ semesters; 3-4 semesters; 5-6 semesters; 7-8 semesters; 9 or more semesters.

The following evaluation criteria was used in the multiple regression modules: $R^{2}$ and $\mathrm{R}_{\text {adj }}^{2}$ was used to determine the percent of variation and variance in the dependent variable as well as to compare different regression models in terms of finding the strongest fit; and the significance of the individual predictor variables was determined by using t-statistics.

In terms of dealing with missing data, single items were left unanswered. Indices were calculated as follows. The Self-Efficacy score was calculated by finding the average of five responses. If only one item was missing the average of the four remaining responses was calculated. If more than one item was missing, the index was left blank. Two Outcome Expectation of Exercise scores were calculated by determining the average of either nine or ten responses. If only one item was missing, the average of the remaining responses was calculated. If more than one item was missing, the index was left unanswered. The Decisional Balance index was calculated based on the average of the perceived barriers to exercise subtracted from the average of the perceived benefits 
of exercise. If more than two out of sixteen items were left unanswered then the index was left blank.

\section{Limitations of the Study}

Although this study offers new insight into the exercise profile of a population that has not been previously studied for that characteristic, there are limitations inherent in the study design. For example, the study design is cross-sectional, which only shows the exercise behavior of students at one point in time. As such, it does not illustrate how their exercise habits may change if interventions are made.

The weaknesses inherent in survey research (i.e., respondent does not complete the questionnaire, someone else completes the questionnaire for the respondent, or questions are misunderstood) are also recognized in this study. The fact that responses gathered from a heterogeneous population of students are pooled together may limit the applicability of the results to specific groups (i.e. those with physical limitations who walked with a cane compared to those who use a wheelchair).

Another potential limitation is that the study was completed in one region of California. As a result, respondents may have different experiences than those from other regions of California or from other states. Although it is suspected that there are many similarities in exercise and APE participation, there may be differences in opinions about access, benefits, and special education courses. Therefore, it may not be possible to generalize the findings to community colleges outside of San Diego County.

It is a concern that each community college is made up of its own culture which affects how APE is advertised and enrollment is recommended to students. An example, one college might pre-register students in APE courses through the DSPS office and this 
might increase enrollment. Another college might have the physical education department direct APE courses and there may be little assistance in course enrollment for students with disabilities. This may make generalizing the findings to other schools more difficult. It is for this reason that it was important to collect the survey at as many different colleges as feasible.

I am aware that my position as a physical education instructor had the ability to affect students' responses. It is even possible that a maximum of ninety students from three colleges may have taken an APE class in which I instructed more than three years ago. During the course of survey collection, I had contact with only two students whom I had previously taught. Therefore, it is doubtful that my past position as an adapted physical education instructor within three of the colleges impacted the data.

There may be students with disabilities who do not want to register with DSPS. Unfortunately, I was not able to receive their comments through my survey. Reasons why students may not register with DSPS are that they do not want to be recognized as being disabled and they may not feel that extra educational services are necessary for them to excel in higher education. If they do not feel extra services or special classes would be helpful, they may not need APE and could, therefore, enroll in regular physical education classes.

Students who experienced difficulty filling out the questionnaire may have had others complete it for them. In fact, one student commented that she needed assistance from her mother to complete the survey. The qualitative questions provided an opportunity for me to read about their experiences living with a disability and thoughts on APE. Although I cannot be positive, these qualitative answers appeared authentic to me 
and gave me the impression they were written in the words of students with disabilities, not a spokesperson. Also, there may be those students who are registered with DSPS and whose severe cognitive disability may prohibit them from communicating, understanding, or answering questions posed to them in any communication style -verbal, written, etc. I have attempted to limit their participation by excluding students whose primary classification was a developmental disability.

A very serious concern was the motivation of students to go to a computer, log into the survey website, and complete the survey. While a mailed packet would have brought the survey to the students' doorsteps, the cost of print, postage, and data entry were compared to the cost savings of an internet survey. More students might have completed a mailed survey, but, due to high costs a smaller sampling of the population would have had to have been targeted. Taking the risk of having fewer students complete an online survey, but being able to recruit a complete population of students, seemed warranted in this case. Especially, since surveying students at only one or two select colleges may very well have produced different findings than surveying students at all colleges in the county. Three diligent efforts were made, through mailed survey invitations and reminders, to collect completed surveys from a large percentage of the population.

\section{Summary}

This chapter reviewed the methodology and procedures implemented to conduct this research. The introduction described the sites and respondents. Then data collection methods, data analysis procedures, and limitations were discussed. The results of the data collection effort are discussed in the following chapter. 


\section{Chapter 4 \\ Presentation of the Findings}

This chapter will include a discussion on the findings, which begins with a description of the survey procedures. The respondents' demographics and exercise participation profiles will be reported next. Reasons for APE avoidance and ideas for APE promotion, as provided by students, are then included. Lastly, results of regression analysis will be used to describe how student demographics and exercise profile components help explain APE enrollment and exercise patterns.

\section{Survey Collection and Time Table}

Respondents completed surveys between September and December, 2006. A copy of the survey can be located in Appendix C and a copy of the survey that contains a complete listing of the final distribution of responses can be found in Appendix D. Most respondents completed the survey on the Survey Monkey website; only twelve students completed the survey by mail. Although nearly 1,200 students were recruited, only 163 surveys were returned. All eight college DSPS departments were helpful participants in this project, but receiving administrative approval at Colleges $\mathrm{B}$ and $\mathrm{C}$ required a lengthy process. Thus, recruitment was delayed at these two schools until very late in the semester, resulting in low respondent rates. Table 1 contains the school enrollments for the fall semester, number of students recruited, and number of respondents at each college. Response rates varied between 8 and $21 \%$, with an average rate of $14 \%$. 
Table 1

Survey Return Rates

\begin{tabular}{lcccc}
\hline College & $\begin{array}{c}\text { Enrollment } \\
\text { Fall 2006 } \\
\text { (headcount) }\end{array}$ & $\begin{array}{c}\text { Number of } \\
\text { Students } \\
\text { Recruited }\end{array}$ & $\begin{array}{c}\text { Number of } \\
\text { Students } \\
\text { Responded }\end{array}$ & $\begin{array}{c}\text { Percentage of } \\
\text { Returned } \\
\text { Surveys }\end{array}$ \\
\hline $\mathrm{A}^{*}$ & 21,325 & 163 & 34 & 21 \\
$\mathrm{~B}^{*}$ & 16,390 & 96 & 10 & 10 \\
$\mathrm{C}$ & 9,816 & 83 & 7 & 8 \\
$\mathrm{D}$ & 13,619 & 139 & 24 & 17 \\
$\mathrm{E} *$ & 16,797 & 76 & 9 & 12 \\
$\mathrm{~F}^{*}$ & 10,533 & 87 & 13 & 15 \\
$\mathrm{G}^{*}$ & 20,781 & 232 & 34 & 10 \\
\hline H & 31,058 & 316 & 32 & 14 \\
Total & 140,319 & 1192 & 163 & \\
\hline * indicates & & & & \\
\hline
\end{tabular}

* indicates schools with Adapted Physical Education.

Population Characteristics

As shown in Table 1, there were 163 survey respondents; the demographic profile of these students is shown in Table 2. Examination of this table shows that more women $(n=87)$ than men $(n=61)$ completed the survey. The age range was 18 to 79 years old with the majority of students falling into the youngest age group, 18 to 29 years old ( $n=$ $68 ; 46.9 \%)$, while the second largest group was the 50 to 59 year olds ( $n=31 ; 21.4 \%)$. When asked to describe their ethnicity, the preponderance of the students identified as White $(n=81 ; 56.6 \%)$ or Hispanic $(n=29 ; 20.3 \%)$. Most students were born with a disability or became disabled during childhood. A majority of the respondents acknowledged that the primary disability they were being served for by DSPS was categorized as an Other Disability $(n=97 ; 65.5 \%)$. There were fewer students being served for Mobility $(n=39 ; 26.4 \%)$ or Visual Impairment $(n=12 ; 8.1 \%)$. One school requested the recruitment of students whose primary disability was an Acquired Brain 
Injury (ABI). Due to the small size of this special category of respondents, they were included in the Other Disability category.

Table 2

Respondent Demographics

$n \quad$ Percent

Gender

$\begin{array}{lll}\text { Women } & 87 & 58.8 \\ \text { Men } & 61 & 41.2\end{array}$

Age

$\begin{array}{rrr}18-29 & 68 & 46.9 \\ 30-39 & 13 & 9.0 \\ 40-49 & 22 & 15.2 \\ 50-59 & 31 & 21.4 \\ 60-79 & 11 & 7.6\end{array}$

Ethnicity

White $\quad 81 \quad 56.6$

Hispanic $\quad 29 \quad 20.3$

African American $\quad 13 \quad 9.1$

$\begin{array}{lll}\text { Asian } & 9 & 6.3\end{array}$

Native American $\quad 3 \quad 2.1$

$\begin{array}{lll}\text { Pacific Islander } & 3 & 2.1\end{array}$

$\begin{array}{lll}\text { Mixed } & 5 & 3.5\end{array}$

Disability Category

Other Disability $\quad 97 \quad 65.5$

Mobility Impaired $\quad 39 \quad 26.4$

Visually Impaired $\quad 12 \quad 8.1$

Age at Onset of Disability

Birth

$0-10$ years old

$11-20$ years old

$21-30$ years old

$31-40$ years old

$41-50$ years old

$51-60$ years old

$61-70$ years old
30

28

28

20

19

15

8

2
20.0

18.7

18.7

13.3

12.7

10.0

5.3

1.3 
Enrollment patterns are included in Table 3. While almost half of the respondents had attended college for four semesters or less $(47.6 \%)$, approximately one fifth were enrolled in their sixth semester $(20.1 \%)$ or had attended more than eight semesters of college (23.5\%). Students were not asked how many semesters they had completed as full-time students, but how many semesters they had taken at least one course; for this reason four semesters of college does not necessarily mean the student has attained junior status. 
Table 3

College Experience

$n$

Semesters of College

$0-2$

$3-4$

$5-6$

$7-8$

9 or more

Taken APE

Yes

No
34

37

30

13

35

36

127

77.9

Number of APE classes taken
1
2
3
4
5

3

4

5

6 or more

Taken Regular PE

Yes

No

$\begin{array}{rr}6 & 18.2 \\ 12 & 36.4 \\ 3 & 9.1 \\ 3 & 9.1 \\ 3 & 9.1 \\ 6 & 18.2\end{array}$

60

36.8

$103 \quad 63.2$

Number of Regular PE classes taken

1

2

3

4

5

6 or more
24

12

10

1

3

10
14.7

7.4

6.1

0.6

1.8

6.1

APE and PE Enrollment

The survey requested information regarding college level physical education enrollment. Table 3 reveals that 60 respondents $(36.8 \%)$ had taken at least one regular PE course and 36 respondents (22\%) had taken at least one APE course at the college 
level. It is interesting that many students took one to two PE or APE courses and that a rather large group of students took six or more classes. Students' future plans for APE or PE enrollment are displayed in Tables 4 and 5: approximately two thirds stated they would be taking neither APE (35.8\%) nor PE (31.3\%). Definite plans for enrolling in APE or PE were expressed by $14.2 \%$ and $17.8 \%$ of respondents, respectively.

Table 4

Frequency Statistics for Future Plans to Take APE $(n=162)$

n Percent

I do NOT ever plan on enrolling in an APE class $58 \quad 35.8$

I am considering enrolling in an APE class in the future $24 \quad 14.8$

I will definitely enroll in an APE class in the future

$23 \quad 14.2$

If an APE class is available at my school, I will enroll

$23 \quad 14.2$

I do not know if I will ever enroll in an APE class

$34 \quad 21.0$

Table 5

Frequency Statistics for Future Plans to Take PE $(n=163)$

n Percent

I do NOT ever plan to enroll in standard PE class $51 \quad 31.3$

I am considering enrolling in a standard PE class $43 \quad 26.4$

I will definitely enroll in a standard PE class

$29 \quad 17.8$

I do not know if I will ever enroll in a standard PE class

$40 \quad 24.5$ 


\section{APE Avoidance}

The survey listed possible reasons why students with disabilities might avoid enrolling in APE. Students were asked to provide their first, second, and third reasons for not enrolling in APE. The five most common reasons why students had not enrolled in APE are given in Table 6. (A complete list of students' reasons for APE avoidance can be located in Appendix E.) Generally, when students had not previously enrolled in APE it was because they exercised on their own, were not aware APE was being offered, or attended regular PE.

Table 6

Top Five Reasons for APE Avoidance $(\mathrm{n}=124)$

I exercise on my own

Write-in response

I am not/was not aware of APE at my school

I attend regular PE

I had not previously heard of APE

In addition, some students provided a write-in response indicating additional reasons for avoidance. Many students commented that they did not need to fulfill a PE requirement as they had already completed a degree or military training: "I am a retired navy and do not have to do P.E. class." Some explained that their disability did not limit physical movement: "I have ADD it does not affect me physically it only affects my concentration on school work." Others admitted that their health problems, whether they were physical or mental-emotional, were too great an obstacle to maintaining an exercise program or attending APE: "With my illness, I have to conserve every little bit of energy I have for just getting through daily life." Still, some stated they did not have the time or motivation to take a physical education course: "I prefer to study and read more than to 
[exercise] even though I know how important it is to [exercise]". One of the important findings is that some students at schools with APE were not aware that APE was even being offered. Some students recognized how lack of knowledge about APE was a barrier to enrolling in it; this led students to provide ideas for promoting APE within their school.

\section{APE Promotion}

An open-ended question asked students to suggest ways to better promote APE on campus. Ninety-nine students responded to this question; 22 out of 99 respondents commented that the classes need to be better advertised. This was a comment made by a student at College B, a school with a long-standing APE program: "More positive advertisement on the programs. I've actually never heard of specialized PE courses until this survey!" Several other students who attend colleges with APE mentioned how they had not previously known APE was available on their campus. In fact, these comments corroborate with the third and fifth most common reasons why students had not taken an APE course (Table 6). Other more specific ideas were to: post flyers; have DSPS counselors inform students through counseling meetings or DSPS orientations; and have the APE instructors promote the classes.

In addition to advertising APE courses, students thought it would be beneficial to promote the benefits of participating in the class and partaking in regular exercise. Two typical comments included: "In order to stay healthy, you have to be physical[ly] active." and "I sincerely believe physical education and exercise keep the mind alert [and] make one feel that he/she accomplishes something, etc. Also, [physical activity] make[s] one feel better and give[s] students who enroll a sense of well being." Importantly, students' 
list of benefits is similar to those mentioned in chapter one of this paper. Some students with disabilities recognized that physical activity improves physical, mental, and social health, and can result in a greater sense of accomplishment and well-being.

\section{Colleges With and Without APE}

To study the effect that being a student at a college with APE might have on exercise variables, a sample t-test was utilized. Though students at colleges with APE consistently scored higher on the exercise scales than their counterparts at colleges without APE, the difference was not statistically significant. Therefore, it seems that offering APE at a school does not make any difference in regard to students' stage of exercise, exercise self-efficacy, outcome expectations for exercise, or decisional balance of exercise.

Exercise Indices

The exercise profile consisted of the physical education histories and future plans, which were discussed earlier, and also of the four scales examining exercise mediators, factors believed to influence exercise behavior. The four scales measured stage of exercise, exercise self-efficacy, outcome expectations for exercise, and decisional balance of exercise. However, before discussing the results of the scales, the details of a slightly modified outcome expectations for exercise scale will first be presented.

Outcome expectations for exercise. One's belief that participating in physical activity will lead to desired outcomes has been coined "outcome expectations for exercise". Two scales, one including nine questions and the other including ten questions, were utilized to measure the students' expectations for exercise. The only difference between scales was the addition of a question about body weight, "Exercise 
helps me get to a healthy weight or maintain my weight", into the ten-item scale. To determine whether the nine- or ten-item scale was a better indicator of one's expectations for exercise, a statistical analysis compared the two scales. A correlation was run to determine if the additional question added to the quality of the scale. The Pearson correlation coefficient for the body weight question was $.676(p<0.01)$. The reliability analysis determined Chronbach's alpha for the nine-item scale to be .920 and slightly higher, .922 , for the ten-item scale. Chronbach's alpha should be over 7 to indicate a strong fit. Though there was not a significance difference between the scales' Chronbach alpha scores, the tenth item was deemed an appropriate fit to this index. As such, further discussion will only refer to the ten-item outcome expectations for exercise scale.

Descriptive statistics for the four exercise scales. Descriptive statistics for the four exercise indices representing stage of exercise, exercise self-efficacy, outcome expectations of exercise and decisional balance of exercise are presented in Table 7.

Table 7

Descriptive Statistics for Exercise Variables

\begin{tabular}{lccc} 
Variables & $n$ & Mean & Standard Deviation \\
Stage of Exercise & 162 & 3.46 & 1.25 \\
Exercise Self-efficacy & 157 & 2.66 & .94 \\
Outcome Expectations for Exercise & 159 & 3.97 & .76 \\
Decisional Balance of Exercise & 151 & 1.27 & 1.25 \\
\hline
\end{tabular}

Descriptive statistics for the stage of exercise scale can be found in Table 8 . The largest groups of students reported that they were preparing to begin an exercise program 
$(\mathrm{n}=52 ; 32.1 \%)$ or had been maintaining a regular exercise program for at least six months $(n=49 ; 30.2 \%)$.

Table 8

Percent of Participants in Each Stage of Exercise $(n=162)$

Stage of Exercise

Precontemplation

Contemplation

Preparation

Action

Maintenance $n \quad$ Percent

$10 \quad 6.2$

$27 \quad 16.7$

$52 \quad 32.1$

$24 \quad 14.8$

$49 \quad 30.2$

APE, PE, both, or neither. Table 9 provides the results of the independent sample t-tests on four exercise indices. When comparing those students who had taken APE to those students who had not, a trend was discovered; students who had taken APE scored higher on all of the scales than those who had not taken APE. Still, the only indices to show a significant difference between groups were the stage of exercise and decisional balance scales. Respondents who previously completed or were currently enrolled in APE scored significantly higher $(\mathrm{P}=0.05)$ than those who had not taken an APE class ( 3.86 vs. 3.35$)$ on the stage of exercise scale. Therefore, students who had enrolled in APE were more likely to engage in physical activity and find more advantages in exercise than students who had never enrolled in APE $(p=0.05)$. 
Table 9

t-Test Comparison of Those Who Have Taken APE vs. Those Who Have Not

APE class $\quad$ No APE

$\begin{array}{llllll}\text { Variable } & \text { Mean } & \begin{array}{l}\text { Standard } \\ \text { Deviation }\end{array} & \text { Mean } & \begin{array}{l}\text { Standard } \\ \text { Deviation }\end{array} & \mathrm{t} \\ \text { SOE } & 3.86 & 1.06 & 3.35 & 1.28 & 2.13^{*} \\ \text { ESE } & 2.76 & 0.86 & 2.63 & 0.96 & 0.70 \\ \text { OEE } & 4.14 & 0.75 & 3.93 & 0.76 & 1.48 \\ \text { DB } & 1.64 & 1.22 & 1.16 & 1.25 & 1.96^{*}\end{array}$

Note. $\mathrm{SOE}=$ Stage of Exercise; $\mathrm{ESE}=$ Exercise Self-Efficacy; OEE $=$ Outcome Expectations for Exercise; $\mathrm{DB}=$ Decisional Balance. ${ }^{*} p \leq .05$.

Table 10 provides the results of a series of independent sample t-tests on four exercise indices. Respondents who previously completed, or were currently enrolled in, a regular PE class scored significantly higher $(\mathrm{P}=0.05)$ on the stage of exercise, outcome expectation, and decisional balance scales than those who had not completed at least one regular PE class. While there was a trend for students to also score higher on the selfefficacy scale the difference was not significant. Therefore, when compared to students who had not taken a college level PE course, community college students with disabilities who had taken at least one PE course were more likely to participate in physical activity, have higher expectations of exercise, and believe exercise has more benefits than barriers. 
Table 10

t-Test Comparison of Those Who Have Taken Regular PE vs. Those Who Have Not

PE class

Mean

3.83

2.71

4.13

1.68
Standard

0.97

0.83

0.67

1.07
No PE

Mean Standard $\quad \mathrm{t}$

Deviation

1.35

1.00

$3.16^{* *}$

3.25

2.63

3.88

1.03
0.79

0.50

2.04*

1.29

Note. $\mathrm{SOE}=$ Stage of Exercise; $\mathrm{ESE}=$ Exercise Self-Efficacy; OEE = Outcome Expectations for Exercise; DB $=$ Decisional Balance. ${ }^{*} p \leq .05, *^{*} p \leq .01, *^{* *} p \leq .001$.

It was not enough to examine only the effect of APE enrollment history on students' exercise profiles. Some students with disabilities may have taken regular PE or both APE and PE; these different patterns of physical education enrollment could possibly affect how students scored on the four exercise scales. Consequently, independent t-tests were run to compare four groups of students. Comparisons were made between those who had taken: neither APE nor PE $(n=90)$; both APE and PE $(n=$ 24); only APE ( $\mathrm{n}=11)$; and only PE $(\mathrm{n}=35)$.

One would expect the largest difference to be between students who had taken both types of classes compared to those who had taken neither. This was true: stage of exercise, outcome expectations for exercise, and decisional balance indices were significantly higher when a student had taken both APE and PE than when neither class had been taken (Table 11). Stage of exercise and decisional balance scores were significantly higher for those students who had taken PE compared to those who had 
taken neither PE nor APE (Table 12). Also, exercise self-efficacy ratings were significantly higher in students who had taken both compared to those who had only taken APE. (Table 13)

Table 11

t-Test Comparison of Those Students Who Had Taken Neither APE nor PE vs. Those Students Who Had Taken Both APE and PE

No APE \& No PE

SD

1.38

0.99

0.82

1.31

3.24

2.67

3.88

1.02
APE \& PE

Mean

SD

t

Variable Mean

4.08

2.95

0.98

0.70

0.80

1.18

4.24

1.86

$-1.31$

$-1.95^{*}$

$-2.81^{* *}$

Note. $\mathrm{SOE}=$ Stage of Exercise; ESE = Exercise Self-Efficacy; OEE = Outcome Expectations for Exercise; $\mathrm{DB}=$ Decisional Balance. ${ }^{*} p \leq .05,{ }^{* *} p \leq .01,{ }^{* * *} p \leq .001$.

Table 12

t-Test Comparison of Those Students Who Had Taken Neither APE nor PE vs. Those Students Who Had Taken Only PE

No APE \& No PE

PE only

$\begin{array}{lccccc}\text { Variable } & \text { Mean } & \text { SD } & \text { Mean } & \text { SD } & t \\ & & & & \\ \text { SOE } & 3.24 & 1.38 & 3.66 & 0.94 & -1.95^{*} \\ \text { ESE } & 2.67 & 0.99 & 2.53 & 0.88 & 0.69 \\ \text { OEE } & 3.88 & 0.82 & 3.88 & 0.82 & -1.19 \\ \text { DB } & 1.02 & 1.31 & 1.55 & 0.98 & -2.12^{*}\end{array}$

Note. SOE = Stage of Exercise; ESE = Exercise Self-Efficacy; OEE = Outcome Expectations for Exercise; $\mathrm{DB}=$ Decisional Balance. ${ }^{*} p \leq .05$. 
Table 13

t-Test Comparison of Those Students Who Had Taken APE and PE vs. Those Students Who Had Taken Only PE

APE \& PE

\begin{tabular}{|c|c|c|c|c|c|}
\hline Variable & Mean & SD & Mean & $\mathrm{SD}$ & $\mathrm{t}$ \\
\hline SOE & 4.08 & 0.98 & 3.36 & 1.12 & 1.94 \\
\hline $\mathrm{ESE}$ & 2.95 & 0.70 & 2.35 & 1.06 & $2.02 *$ \\
\hline OEE & 4.24 & 0.80 & 3.92 & 0.60 & 1.18 \\
\hline $\mathrm{DB}$ & 1.86 & 1.18 & 1.13 & 1.23 & 1.61 \\
\hline
\end{tabular}

Note. $\mathrm{SOE}=$ Stage of Exercise; ESE $=$ Exercise Self-Efficacy; OEE $=$ Outcome Expectations for Exercise; $\mathrm{DB}=$ Decisional Balance. ${ }^{*} p \leq .05$.

There was no difference for any of the measures when a student had taken only APE compared to a student who had taken neither APE nor PE. Also, no difference was noted when a student had taken both APE and PE compared to a student who had taken only regular PE. And though there was a trend for all scores to be rated higher when students had taken only regular PE compared to students who had taken only APE, significance was not reached.

Indicators of Physical Education Enrollment

Multiple regression analysis was used to determine if the demographic and exercise profile information collected - gender, age, ethnicity, disability, age at disability onset, semesters of college, school of attendance, and ratings on the stage of exercise, exercise self-efficacy, decisional balance, and outcome expectations for exercise indices - explained APE enrollment patterns. In constructing the ethnicity categories used for regressions, only those categories including more than five respondents were used. 
Removing three small categories was necessary to reduce the chance of outliers confounding the data. Preliminary data analyses demonstrated the strong impact that the Pacific Islander and Native American groups had on regression analyses; both of these groups contained only three completed surveys yet produced significant results because one or two respondents, respectively, had taken at least seven physical education courses which was thought to not be a true representation of the minority group and would have produced unreliable findings.

The first regression model utilized APE enrollment as the dependent variable with exercise profile and demographic components as the independent variables. The binary logistic regression produced only one significant predictor of APE enrollment: semester of college. For every one to two years of college a student attends, he or she is significantly more likely to enroll in an APE course (Coefficient $=.511$, S.E. $=.151 ; \mathrm{p} \leq$ $.001)$.

The second regression model used the number of APE classes as the dependent variable, and stepwise regression analysis resulted in an adjusted $\mathrm{R}^{2}=.13, \mathrm{~F}(2,330)=$ $10.70, p<.000$. (Table 14 ) In this model, approximately $15 \%$ of the variation and $13 \%$ of the variance in number of APE classes taken was explained by two variables. In order of significance, the two predictors were number of college semesters completed and decisional balance. Both had a positive influence on number of APE classes taken. Every one to two semesters of college is associated with one-third more of an APE course; every three years of college is associated with enrollment in another APE course. Similarly, every one point increase on the decisional balance scale is associated with a quarter more of an APE course completed. Remarkably, when changing the dependent 
variable to the number of regular PE classes taken, the same two predictors - semester of college and decisional balance - were found to be significant as well.

Table 14

Regression Analyses for Number of APE and PE courses taken (Only Statistically Significant Variables Shown)

Variable

Estimated Coefficient

$\mathrm{t}$

Number of APE courses

Semesters of College .30

Decisional Balance

Number of PE courses

Semesters of College

${ }^{*} p \leq .05,{ }^{* *} p \leq .01, * * * p \leq .001$

The stepwise regression for number of regular PE classes resulted in an adjusted $\mathrm{R}^{2}=.18, \mathrm{~F}(2,420)=15.43, \mathrm{p}<.000$. (Table 14) Approximately $20 \%$ of the variation and $18 \%$ of the variance in number of regular PE classes taken was explained by two variables; in order of significance, the two predictors were number of college semesters completed and decisional balance. Both had a positive influence on number of PE classes taken. In fact, every one to two semesters of college is associated with more than a one-third increase in PE courses completed; every three years of college is associated with enrollment in another PE course. Every one point increase on the decisional balance scale is associated with more than a one-third increase in PE courses completed.

In addition to addressing the three research questions, the investigator was also interested in identifying what specific exercise profile and demographic components 
contributed the most to each of the four exercise indices. The stepwise regression for stage of exercise resulted in an adjusted $\mathrm{R}^{2}=.27, \mathrm{~F}(3,198)=17.06, \mathrm{p}<.00$. Approximately $29 \%$ of the variation and $27 \%$ of the variance in stage of exercise change score can be explained by three variables. In order of significance, the three predictors were decisional balance, exercise self-efficacy, and attending College G. As shown in Table 15, decisional balance and self-efficacy scores were found to have a positive influence, while attending College $\mathrm{G}$ was found to have a negative influence on stage of exercise change. For every one point increase in decisional balance or self-efficacy score, there was approximately a one third increase in stage of exercise score. Students attending College $\mathrm{G}$ had a half point decrease in stage of exercise score.

Table 15

Regression Analysis for Stage of Exercise (Only Statistically Significant Variables Shown)

Variable

Estimated Coefficient

$\mathrm{t}$

Decisional Balance of Exercise .35

Self-Efficacy of Exercise

${ }^{*} p \leq .05,{ }^{* *} p \leq .01,{ }^{* * *} p \leq .001$

The stepwise regression for exercise self-efficacy resulted in an adjusted $\mathrm{R}^{2}=.19$, $\mathrm{F}(2,119)=52.39, \mathrm{P}<.00$. About $20 \%$ of variation and $19 \%$ of the variance in exercise self-efficacy can be explained by two variables. In order of significance, the two predictors were decisional balance and stage of exercise scores. As shown in Table 16, both independent variables were found to have a positive influence on exercise self- 
efficacy. For every one point increase in decisional balance or stage of exercise score, exercise self-efficacy increased two-tenths of a point.

Table 16

Regression Analysis for Exercise Self-Efficacy (Only Statistically Significant Variables Shown)

Variable

Estimated Coefficient

$\mathrm{t}$

Decisional Balance of Exercise .20

${ }^{*} p \leq .05,{ }^{*} p \leq .01, * * * p \leq .001$

The stepwise regression for decisional balance of exercise resulted in an adjusted $\mathrm{R}^{2}=.51, \mathrm{~F}(3,212)=45.41, \mathrm{p}<.00$. Approximately $52 \%$ of the variation and $51 \%$ of the variance in decisional balance are explained by three variables. In order of significance, the three were outcome expectations for exercise, age (18 - 29 years old), and stage of exercise. As illustrated in Table 17, both outcome expectations and stage of exercise change were found to have a positive impact on decisional balance, but being in the 18 to 29 year old age group had a negative impact. Each point increase in outcome expectations for exercise corresponds with almost a one point increase in decisional balance. Every one point increase in exercise stage is associated with a quarter increase in decisional balance. Students between the ages of 18 to 29 scored more than one-half point lower on the decisional balance scale. 
Table 17

Regression Analysis for Decisional Balance of Exercise (Only Statistically Significant Variables Shown)

Variable

Estimated Coefficient

$\mathbf{t}$

Outcome Expectations for Exercise

.93

$-.54$

$7.90 * * *$

Age Group (18 - 29)

.23

$-3.36 * * *$

Stage of Exercise

$3.31 * * *$

${ }^{*} p \leq .05,{ }^{* *} p \leq .01,{ }^{* * *} p \leq .001$

The stepwise regression for outcome expectations for exercise resulted in an adjusted $\mathrm{R}^{2}=.44, \mathrm{~F}(2,70)=52.39, \mathrm{p}<.00$. As illustrated in Table 18 , approximately $45 \%$ of the variation and $44 \%$ of the variance in outcome expectations for exercise are explained by two variables. In order of significance, the two were decisional balance and identifying as African American. While decisional balance had a positive impact, being African American had a negative impact on outcome expectations for exercise. Every one point increase on the decisional balance scale is associated with more than a onethird increase in outcome expectations for exercise. African American students scored over one-third point lower on the outcome expectations for exercise scale than nonAfrican Americans. 
Table 18

Regression Analysis for Outcome Expectations for Exercise (Only Statistically Significant Variables Shown)

Variable

Estimated Coefficient

t

Decisional Balance of Exercise $\quad .38$

African American

$-.37$

$10.12^{* * *}$

$-2.21^{*}$

${ }^{*} p \leq .05, * * p \leq .01, * * * p \leq .001$

Overall, exercise indices strongly interacted with each other. Identification as being a young or an African American student negatively impacted decisional balance and outcome expectations, respectively. Predictors of the number of APE courses taken are the same as those that predict the number of PE courses taken: semesters of college and decisional balance. 
Chapter 5

Summary, Implications, and Recommendations

The purpose of this study was to: (a) describe the demographics and exercise participation profiles of community college students with disabilities; (b) document reasons why some San Diego community college students with disabilities do not participate in APE; and (c) determine to what extent student demographics and exercise profile components help explain why some students with disabilities enroll in adapted physical education (APE) courses and some do not. The final chapter of this dissertation is divided into four sections. The first section includes a summary of the research methodology. The second evaluates the findings. Next, policy implications for community colleges are discussed and, finally, the chapter concludes with suggestions for future research regarding community college APE programs and recruitment.

\section{Summary of the Research Design}

This investigation utilized survey methodology to collect quantitative and qualitative data. Survey invitations were sent out by mail and surveys were completed through an internet-based survey site. Although the respondent rate was less than expected at $14 \%$, surveys were collected from 163 community college students with disabilities in one Southern California County. There are several possible reasons for the low response rate: type and severity of disability may have prevented students from completing the survey; students may not have had easy access to the technology they needed to complete the survey; and some students with non-physical disabilities, such as Attention Deficit Hyperactivity Disorder, who were included in the Other Disability category recognized that the investigation was not intended for them and, subsequently, 
refused to complete it. Fortunately, 163 completed surveys provided enough data to allow the investigator to proceed into previously undocumented territory and complete statistical analyses on a population largely untargeted by researchers since the initial descriptive papers published in the late 1970s and early 1980s.

While internet-surveys have become an increasingly popular avenue for data collection, it is now suspected that surveys by mail or interview may have produced a larger survey return rate for this investigation. Community colleges in this region do not yet have a system in place to secure current and accurate email addresses for all of their students, which would have made an email-generated survey invitation challenging. In addition, it is probable that some students in the target population may experience more difficulty in completing a survey, let alone an internet survey, due to their disability. Therefore, unless schools have current email addresses for students, undertaking an internet survey may not yet be the best option when gathering data from California community college students, especially those with disabilities.

The investigator collected quantitative data on demographics such as gender, age, ethnicity, disability type, age at onset of disability, semesters of college attended, and reasons for adapted physical education avoidance. In addition to demographic data, patterns of physical activity and views on exercise were also assembled; this was collectively called the exercise profile. The exercise profile included APE and regular PE enrollment patterns and the results of four scales: stage of exercise change, exercise selfefficacy, outcome expectations for exercise, and decisional balance of exercise. Scores from the four scales were computed and further analyzed to better understand their role as mediators of exercise, which are those factors that lead to change in behavior (Marcus 
and Forsyth, 2003). In addition, qualitative questions were designed to collect students' write-in responses for reasons of avoidance of APE, ideas for better promotion of APE, and experiences with the survey.

\section{Evaluation of the Results}

Data were collected from 163 students representing all eight community colleges in one Southern California County; in this sample, both men (41.2\%) and women (58.8\%), and white (56.6\%) and minority (43.4\%) students were well represented. It is not surprising that the largest group of students was young; $46.9 \%$ of students were between 18 and 29 years old. However, it was surprising that the second largest age group, $21.4 \%$ of responders, was between 50 and 59 years old. This statistic supports the prediction that the baby boomers are returning to school (Thompson, 2003), but the trend, often called Tidal Wave II, is arriving a bit earlier than expected as the front end of baby boomers do not reach the retirement age of 65 until 2011.

Most of the students who completed the survey described themselves as being in the "Other Disability" category (65.5\%), but those with mobility impairments $(26.4 \%)$ and visually impairments (8.1\%) also completed the questionnaire. When comparing the proportion of disability groups between those who responded and the larger population that was invited to take the survey, the percentages were very similar: Other Disability $(64 \% ; n=763)$; mobility impairment $(29 \% ; n=341)$; and visual impairment $(7 \% ; n=$ 88). Thus, the respondents are a fair representation, by disability category, of community college students fitting the inclusion criteria.

Interestingly, the study indicated that students with disabilities who had completed the survey were more likely to have taken a regular PE class $(36.8 \%)$ than an 
APE class (22.1\%), but only slightly more were confident they would enroll in a regular PE class (17.8\%) than an APE class (14.2\%). Yet, these numbers represent the original reason why the researcher designed this investigation: to better understand why eligible students do not take APE courses. Since forty-five percent of the students were already exercising (Table 8), it was not surprising that the most common reason provided for not taking APE is that they already exercise on their own. Two other popular reasons for APE avoidance were that students had not previously heard of APE or were not aware that it was part of their school's curriculum. These two reasons can be easily addressed by better advertising APE courses. Fortunately, respondents had insightful ideas for APE promotion which will be revealed later in the policy section after a discussion on the use of the transtheoretical model of behavior change.

The transtheoretical model (TTM) was utilized in the current study as a way to stage students' level of exercise. As suggested by Marshall and Biddle (2001), mediators of exercise, factors that lead to behavior change, were also incorporated in the form of exercise self-efficacy, outcome expectations for exercise, and decisional balance scales. First, the results will be given for the stage of exercise scale and then results from the three mediators of exercise change will be provided.

The mean stage of exercise score of $3.46(\mathrm{SD}=1.25$; Table 7$)$ reveals that a large proportion of students were preparing to add exercise to their lifestyle or were already regularly exercising. The frequencies for the stage of exercise model were presented in Table 8: $6.2 \%$ were not exercising and did not plan to start exercising in the next six months; $16.7 \%$ were thinking about starting an exercise program; $32.1 \%$ were presently getting some exercise, but not regularly; $14.8 \%$ were regularly participating in at least 20 
minutes or more of exercise on three or more days per week, but had only started doing so within the past six months; and $30.2 \%$ had been regularly participating in at least 20 minutes or more of exercise per session for longer than six months. When adding together students in the action and maintenance stages of exercise, nearly half, approximately $45 \%$, of students self-reported that they were participating in regular exercise.

In comparison, students with disabilities in the current study were three times more likely to be exercising at a rate of 20 minutes three times per week than reported in the baseline data collected in 1997 from the Healthy People 2010 (HP2010); the HP2010 report indicated that only $16 \%$ of adults with disabilities were regularly participating in exercise (CDCP, 2004). The large difference may indicate that more adults with disabilities have begun exercising in the past 10 years, the methodology for collecting rates of exercise produced different results, not all students were able to adequately selfreport current exercise levels, or students with disabilities are more likely than adults with disabilities to participate in regular exercise. The latter reason, though, is not supported when comparisons are made between the students with disabilities and subjects in two of Cardinal's studies.

In 2004, Cardinal studied 322 adults with physical disabilities and determined more than half of participants were in the maintenance stage of change (53.7\%), followed by the precontemplation (18.9\%) and action (11.8\%) stages. In comparison with Cardinal's study, the community college students with disabilities in this study were not doing as well in maintaining an exercise program as there were less in the maintenance stage (30.2\%) and more in the preparation stage (32\%). In 1995, Cardinal completed a 
study inquiring into the exercise habits of non-disabled female adults; his findings produced results closer to the students in this study: the largest groups were in the preparation (37.6\%) or maintenance stage $(23.0 \%)$. Therefore, although the college students in the current study are similar to other groups in regard to their exercise patterns, they were more likely to participate in exercise than the all-female group, but less likely than the adults with physical disabilities. Reasons for differences may be due to lack of knowledge about exercise or affordable classes, available free time, or even how the questionnaire was presented.

Although, there is little data available to compare the college students in this study to other college students with disabilities, a comparison can be made with nondisabled college students. As stated in the literature review, less than half of students surveyed in the late 1990's were regularly exercising (Douglas, 1997; Pinto, 1995), with lower rates for female than male students (Sallis, 1999). Surprisingly, students with disabilities in the current study were found to exercise at similar rates to the students in these other studies.

As shown in Table 15, regression analysis was conducted using stage of exercise change as the independent variable. Both decisional balance and exercise self-efficacy scales predicted an increased stage of exercise score. Attending College G was associated with a decreased stage of exercise score which seemed to be a counterintuitive finding, especially since there is an extensive offering of PE and APE courses, a longstanding APE program, and a very involved instructor teaching APE at College G. Considering the possibility that a low number of respondents may have taken a physical education course at College $\mathrm{G}$, a calculation was made into the number of respondents 
who had taken a college level physical education course: $44 \%$ of the respondents from College $\mathrm{G}$ had taken some type of college-level physical education course, which was comparable to the range $(25-53 \%)$ for all colleges in the study.

Possibly, another characteristic of the College $G$ population may help explain the low exercise levels in students with disabilities: $56 \%$ of the respondents at College $\mathrm{G}$ identified as Hispanic, a full two-thirds of the total number of Hispanic respondents in the study. Suminski (2002a) found that Hispanic students were at the greatest risk of being in a non-exercise stage when compared to White, Asian, or African American students. If ethnicity was the main cause then one might expect that being Hispanic would have been a major predictor of stage of exercise in this study, but it was not. Yet, when nonHispanic respondents from all colleges were grouped together their mean stage of exercise score (3.56, SD 1.25) was significantly higher than the Hispanic respondents' mean score (3.03, SD 1.18; $\mathrm{p}<.05)$. Only 4 out of 19 Hispanic students $(21 \%)$ from College $\mathrm{G}$ were exercising; this low percentage may be the main cause for the mean stage of exercise score at College G. Or, the findings may have had more to do with the structure of the physical education courses than the ethnicity of the students. For example, if classes are mainly held in the school's Fitness Center and exclude discussions on home exercise programs, then students may not have the skills to maintain their exercise program after the completion of the course. Or, if students with disabilities do not enjoy their class or have a negative experience while attending it, they may be less apt to maintain an exercise program. Still, another factor affecting the stage of exercise score may be that College $\mathrm{G}$ students with disabilities are more disabled than their peers at other local community colleges. Perhaps, the reason why the mean score for exercise 
stage was lower for College $\mathrm{G}$ is a combination of factors not adequately identified by the survey components.

The mean scores of the other independent exercise variables, exercise selfefficacy, outcome expectations of exercise, and decisional balance of exercise, were presented in Table 7. The exercise self-efficacy index included the average score from five Likert-style questions where answers ranged from one to five. The mean exercise self-efficacy score of $2.66(\mathrm{SD}=.94)$ revealed that students in this study were slightly-tomoderately confident that they would be physically active during different situations. Increasing students' exercise knowledge and offering positive exercise experiences may assist students in becoming more confident in their ability to be physically active.

Outcome expectations for exercise (OEE) are beliefs that participating in exercise will produce desired outcomes. The OEE index included the average score from ten Likert-style questions where answers ranged from one to five. For these questions, lower scores indicate that individuals had fewer expectations for exercise while higher scores indicate that one has more expectations in the power of exercise to produce desirable outcomes. In this study, the average score for the outcome expectations for exercise was $3.97(\mathrm{SD}=.76)$, which represents an acknowledgement by the students of their high expectations of exercise. Not surprisingly, the college students scored higher on the OEE than older adults with a means score of $3.4(\mathrm{SD}=.82$; Resnick, 2000). One might speculate that college students were younger and had more years of life in front of them that could be positively affected by exercise. Also, some older adults, especially women, may have been brought up in a time or culture where exercise was not thought to be an especially appropriate activity. Older women have made comments to the author that 
"sweating" is an uncomfortable and unfamiliar sensation to them as they did not exercise while growing up. Today's young adult population has been exposed to the benefits of exercise and physical activity through schools, the media, and government campaigns. Consequently, younger adults have had more frequent exposure to exercise education than older adults, which may have produced higher expectations of exercise.

Using results from the same study on older adults, Resnick (2000) recommended including the item, "Exercise helps to strengthen my bones" even though she determined the item had lower factor loading (.52) than the other eight questions. To add to the literature and continue to assess reliability of the OEE scale, the current investigation included the "bone" question and added a question on body weight. The Pearson correlation coefficient for the bone question was .682 $(\mathrm{p}<0.01)$ when included in the current study's OEE ten-item scale. In fact, the bone question was a slightly better fit than the body weight question (.676; $\mathrm{p}<0.01)$. Most importantly, the Chronbach's alpha was .922 for the OEE ten-item scale, well over 7 which indicates a strong fit. Future researchers should continue to assess the reliability and validity of the OEE ten-item scale.

Students' perceptions on the advantages and disadvantages of exercise were measured with the decisional balance scale as recommended by Marcus (1992a; 2003). The average score of ten advantages of exercise was subtracted from the average score of six disadvantages of exercise items. Decisional balance scores can range from -4 to +4 with scores less than 0 indicating the respondent perceives more barriers than benefits; the higher a positive score, the more benefits perceived by the respondent. The mean decisional balance score of $1.27(\mathrm{SD}=1.25)$ illustrated how students with disabilities 
perceived there to be more benefits than barriers to physical activity, but their scores can be further increased. Students may recognize more benefits of exercise after participating in a well designed physical education class.

Overall, mean scores on the four exercise indices were adequate, but indicated that efforts can be made to increase students' exercise participation, belief in their ability to exercise, expectations of exercise, and ability to recognize more advantages and less disadvantages to participating in an exercise program. As was demonstrated in Tables 15 -18 , the four exercise indices were strongly related to each other: decisional balance and self-efficacy of exercise were good predictors of stage of exercise change; decisional balance and stage of exercise were good predictors of exercise self-efficacy; outcome expectations for exercise and stage of exercise were good predictors of decisional balance; and decisional balance of exercise was a good predictor of outcome expectations for exercise. Similarly, other researchers have demonstrated the strong positive correlation between exercise self-efficacy and the stages of exercise scale in adults with disabilities (Cardinal, 2004) as well as those without disabilities (Marcus, 1992c). In addition, Kosma (2004) found decisional balance to contribute to stage of exercise prediction in adults with physical disabilities. Comparable to other stage of exercise studies, the current investigation found self-efficacy and decisional balance to be good predictors of exercise stages.

The goal of helping more students reach and maintain higher levels physical activity, as measured by the stage of exercise scale, may be attained by increasing students' exercise self-efficacy and decisional balance scores. Upon closer inspection of the individual items on the scales, a couple of themes immerged; students were 
challenged by lack of time and feelings of fatigue. These are challenges that can be addressed through education and positive experiences with exercise. For example, responses from the self-efficacy scale indicated that 50 students were not confident in their ability to exercise when time was an issue and 43 were not confident they could exercise when feeling tired. Responses from the decisional balance scale indicated that 36 students believed they would be too tired to complete their daily work after being physically active and yet 60 believed they would be too exhausted to be physically active at the end of the day. Perhaps, physical education workshops could increase students' awareness of the important health benefits of exercise (i.e. increased energy) and of better ways to manage time and energy levels, which then may increase their exercise selfefficacy and decisional balance scores. Club meetings, campus health fairs, and college classes all present opportunities where exercise self-efficacy and decisional balance issues can be addressed with the hope of leading more students to physical education classes and physically active lifestyles.

One of the main goals of this study was to determine through regression analysis what demographic and exercise measures explained physical education enrollment patterns. The only significant predictor of whether a student takes APE or not is the length of time a student has been a college student. The longer a student with a disability attends college, the greater chance that APE enrollment will be suggested by DSPS personnel or by other students, recommended by a medical professional to assist with health issues and physical functioning, and used to meet the minimum requirements to receiving financial aid. Also, some students may purposely avoid enrolling in APE until 
they can avoid it no longer and it becomes one of their last course requirements needed in order to graduate.

To determine if there were any other predictors of physical activity course enrollment, regressions were conducted using the number of APE or PE courses a student had enrolled in as dependent variables. (Table 14) Results showed a strong relationship between the number of APE or PE courses enrolled in and semesters of college completed and decisional balance score. Furthermore, the findings indicated that the longer students are in school the greater their chance of completing some type of physical education course, and those students who find more advantages than disadvantages in taking a physical education class have a greater chance of enrolling in a physical activity course. Most of the reasons for APE enrollment provided in the previous paragraph could also apply as possible reasons for PE enrollment. In addition, as students continue taking college courses it is assumed they become more educated on a variety of topics, including health issues. In fact, Health Education is a frequent requirement of the community college Associate degree and at least one chapter in any health education textbook focuses on exercise. Therefore, as students persevere though higher education, they may gather more information about exercise, leading them to a higher score on the decisional balance scale, and causing them to consider taking a physical activity course to improve their health.

Students who had taken a physical activity course, whether it was APE or regular PE, tended to score higher on the stage of exercise, outcome expectations for exercise, and decisional balance scales than students who had taken neither (Tables $9-12$ ). Because the current investigation did not measure severity of disability, one cannot be 
sure how severity and overall disability experiences may have affected avoidance of, or enrollment into, physical education classes. It is quite possible that students with more physical ability or higher exercise self-efficacy, regardless of severity of their disability, would prefer regular PE over APE. The data displayed in Table 13 may provide some support for this hypothesis as exercise self-efficacy was the only scale where there was a difference between students who have taken both APE and PE when compared to APE only. Students who had taken both types of physical education courses had higher exercise self-efficacy. Unfortunately, since the data is not longitudinal, the direction of causality cannot be determined; in other words, one cannot tell if higher exercise selfefficacy led to physical education enrollment or if physical education enrollment led to higher self-efficacy.

\section{Policy Implications}

Where students exercise is not as important as the fact that they participate in cardiovascular, strength, and flexibility training at their ability level. While not all students with disabilities need adapted physical education in order to exercise, APE is often available to assist students in fulfilling their PE requirement or improving their health by learning how to safely and progressively exercise in an instructor-monitored environment. Yet, the qualitative data suggest that there are students who might take advantage of APE if they knew about it as well as the benefits of participation. Respondents provided ideas for increasing APE enrollment and students' knowledge about the benefits of exercise participation which will be discussed in the following section. 
There are many actions that schools can take to increase students' awareness of APE. Schools should ensure they are advertising APE and PE classes to their students with disabilities. Letters can be mailed to students and flyers can be posted in the offices of Disability Support Program and Services (DSPS) which highlight the benefits of exercise as part of a healthy lifestyle and include the college's various APE offerings. In partnership with DSPS staff, the letter could be written and signed by the APE instructor. In addition, $\mathrm{APE}$ and $\mathrm{PE}$ instructors can increase their visibility and approachability by attending orientations, symposiums, and club meetings which students with disabilities attend. Furthermore, DSPS personnel are in an excellent position to invite students of various disabilities, ethnicities, and ages to participate in focus groups where the purpose is to provide appealing ways to positively promote the benefits of APE and PE to all sub groups of students.

While students of all ethnicities should be encouraged to enroll in APE, schools should make strong attempts at encouraging African American and Hispanic students with disabilities to attend exercise courses. Why African American and Hispanic students scored lower on the outcome expectations for exercise and stage of exercise scales, respectively, is not clear; therefore, more research needs to be done in these areas. Of course, differences in experiences, culture, family, and body image may have affected the outcome. Though Cardinal (1997a) did not use regression analysis in his work, he did determine that African-Americans were more likely to be in an earlier stage of exercise than Whites or other minorities. In contrast, Suminski (2002a) found that Hispanic students were more likely to be in an earlier stage of exercise than White, Asian, or African American students. Still, both studies found disparities between the 
exercise levels of minorities compared to white students. Cardinal (1997a) suggested the use of exercise stage-matched invention strategies to increase physical activity within groups: these strategies may include education on the physical, social, and psychological benefits of exercise conducted in a manner that reaches and appeals to all students.

\section{Recommendations for Future Research}

In this section, three recommendations for future research are discussed. The first recommendation is to apply and assess the APE promotion techniques listed by the respondents. Since this study found that some students are not aware of APE or do not understand how exercise can be beneficial, educators need to determine which techniques, or combination of techniques, are most effective at increasing enrollment. The second recommendation involves conducting a longitudinal study to examine how the four exercise scales and various physical parameters, such as endurance, strength, and flexibility, change after actually taking APE. The third recommendation is to research the application of stage-matched interventions for students in an APE course; the instructor could perform pre-testing to determine students' stage of exercise and appropriately design behavioral interventions for students in each stage. For example, when students are determined to be in the action stage, they can be given action plans to help them meet challenges that may decrease their ability to maintain a lifelong exercise program (i.e. illness, vacation, final exams).

Lack of physical education research for community college students with disabilities shows quite strongly the need for further investigations into the short-term effectiveness of physical education classes and the long-term maintenance of lifetime exercise. For example, researchers can partner with college educators to design 
investigations tailored to best fit the characteristics of the school (i.e. physical education programs, fitness centers, and students). The field of APE must move forward through the application of evidence-based quantitative and qualitative research that includes studies on motivation, adherence and barriers to exercise and the relationship between physical activity and health in students with disabilities. The need to conduct more sophisticated research in the field of exercise among adults with disabilities has been recognized by other researchers and government agencies (Cooper, 1999; Morgan, 2001; Reid, 2000).

The results of this investigation reinforce the need to learn more about this underserved population, a population that often experiences significant barriers to beginning and maintaining recommended levels of physical activity. College faculty and staff should not neglect the physical activity needs of students with disabilities, but should emphasize, through physical education programs, the value of participation in exercise and the benefits of lifelong exercise endeavors. 


\section{References}

Adams, T.M. \& Brynteson, P. (1992). A comparison of attitudes and exercise habits of alumni from colleges with varying degrees of physical education activity programs. Research Quarterly for Exercise and Sport, 63(2), 148-152.

Adams, T.M. \& Brynteson, P. (1995). The effects of two types of required physical education programs on attitudes and exercise habits of college alumni. Physical Educator, 52(4),

American College of Sports Medicine. Guidelines for Exercise Testing and Prescription (6 $6^{\text {th }}$ ed). (2000). Baltimore, MD: Lippincott Williams \& Wilkins. Armstrong, K.L., O’Bryant, C., \& Costa, C. (2002). An assessment of the factors that influence the promotion and delivery of sport, fitness, and health courses: Contributions of marketing to physical education. Physical Educator, 59(3), 139151.

Ball, A.E., Russell, E.M., Seymour, D.G., Primrose, W.R., \& Garratt, A.M. (2001). problems in using health survey questionnaires in older patients with physical disabilities. Gerontology, 47, 334-340.

Beasley, C.R. (1982). Effects if a jogging program on cardiovascular fitness and work performance of mentally retarded adults. Journal of Mental Deficiency, 86(6), $609-613$.

Becker, H.A., Stuifbergen, K.I., \& Sands, D. (1989). Health promoting attitudes and behaviors among persons with disabilities. International Journal of Rehabilitation Research, 12(3), 235-250.

Blinde, E.M. \& Taub, D.E. (1999). Personal empowerment through sport and physical 
fitness activity: Perspectives from male college students with physical and sensory disabilities. Journal of Sport Behavior, 22(2), 181-202.

Bradburn, N., Seymour, S. \& Wansink, B. Asking Questions (rev. ed.) (2004). San Francisco, CA: Jossey-Bass.

Buckworth, J. (2001). Exercise adherence in college students: Issues and preliminary results. Quest, 53, 335-345.

Buono, M.J., McKenzie, T.L., \& McKenzie, R.E. (1988). Effects of a diet and exercise program on blood lipids, cardiorespiratory function, and body composition in obese women. Journal of the American Kinesiotherapy Association, 42(1), 22-26.

California Community Colleges Adapted Physical Education Handbook. (2002, June). California Community Colleges Chancellor's Office (2004). Home Page. Retrieved On November 11, 2004, from http://www.cccco.edu/.

Cardinal, B.J. (1992). Wellness-fitness programming for persons with disabilities: Unique approaches and special considerations. Wellness Perspectives, 8(3), 6064.

Cardinal, B.J. (1995a). Behavioral and biometric comparisons of the preparation, action, and maintenance stages of exercise. Wellness Perspectives: Research, Theory, and Practice, 11(3), 36-43.

Cardinal, B.J. (1995b). The stages of exercise scale and stages of exercise behavior in female adults. The Journal of Sports Medicine and Physical Fitness, 35, 87-92.

Cardinal, B.J. (1997a). Construct validity of stages of change for exercise behavior. American Journal of Health Promotion, 12(1), 68-74.

Cardinal, B.J. (1997b). Predicting exercise behavior using components of the 
transtheoretical model of behavior change. Journal of Sport Behavior, 20(3), $272-283$.

Cardinal, B.J. (1998). Interaction between stage of exercise change and history of exercise relapse. Journal of Human Movement Studies, 34, 175-185.

Cardinal, B.J., Kosma, M. \& McCubbin, J.A. (2004). Factors influencing the exercise behavior of adults with physical disabilities. Medicine \& Science in Sports \& Exercise, 36(5), 868-875.

Carlson, J.E., Ostir, G.V., Black, S.A., Markides, K.S., Rudkin, L. \& Goodwin, J.S. (1999). Disability in older adults 2: Physical activity as prevention. Behavioral Medicine, 24(4), 257-168.

Centers for Disease Control and Prevention (2004). Healthy People 2010 Objectives for People with Disabilities. Retrieved on December 13, 2004, from http://www.cdc.gov/ncbddd/dh/hplhidata.htm

Chanias, A.K., Reid, G., \& Hoover, M.L. (1998). Exercise effects on health-related physical fitness of individuals with an intellectual disability: a meta-analysis. Adapted Physical Activity Quarterly, 15, 119-140.

Cooper, R.A., Quatrano, L.A., Axelson, P.W., Harlan, W., Stineman, M., Franklin, B. et al. (1999). Research on physical activity and health among people with disabilities: A consensus statement. Journal of Rehabilitation Research and Development, 36(2), 142-154.

Corbin, C.B. (2002a). Physical activity for everyone: What every physical educator should know about promoting lifelong physical activity. Journal of Teaching in Physical Education, 21, 128-144. 
Corbin, C.B. (2002b). Physical education as an agent of change. Quest, 54, 182-195.

Cox, K.L., Gorely, T.J., Puddey, I.B., \& Beilin, L.J. (2003). Exercise behaviour change in 40 to 65-year-old women: The SWEAT study (Sedentary Women Exercise Adherence trial). British Journal of Health Psychology, 8, 477-495.

Crain, C. (1982). Dance for special populations. Journal of Physical Education, Recreation \& Dance, 53(7), 70-72.

Croce, R.V. (1990). Effects of exercise and diet on body composition and cardiovascular fitness in adults with severe mental retardation. Education and Training in Mental Retardation, 25, 176-187.

Dearden, J.S. \& Sheahan, S.L. (2002). Counseling middle-aged women about physical activity using the stages of change. Journal of the American Academy of Nurse Practitioners, 14(11), 492-495.

Dishman, R.K., Washburn, R.A. \& Schoeller, D.A. (2001). Measurement of physical activity. Quest, 53, 295-309.

Douglas, K.A. \& Collins, J.L. (1997). Results from the 1995 National College Health Risk Behavior Survey. Journal of American College Health, 46(2), 55-67.

Duffy, N.W. (1979). Independent study in physical education for exceptional students. Journal of Physical Education and Recreation, 50(9), 24.

Dunn, A.L., Marcus, B.H., Kampert, J.B., Garcia, M.E., Kohl, H.W. \& Blair, S.N. (1997). Reduction in cardiovascular disease risk factors: 6-month results from Project Active. Preventive Medicine, 26, 883-892.

Durstine, J.L., Painter, P., Franklin, B.A., Morgan, D., Pitetti, K.H. \& Roberts, S.O. (2000). Physical activity for the chronically ill and disabled. Sports Medicine, 
$30(3), 207-219$

Ginis, K.A.M., Latimer, A.E., McKechnie, K., Ditor, D.S. \& McCartney, N. (2003).

Using exercise to enhance subjective well-being among people with spinal cord injury: The mediating influences of stress and pain. Rehabilitation Psychology, 49(3), 157-164.

Guthrie, S.R. (1999). Managing imperfection in a perfectionistic culture: Physical activity and disability management among women with disabilities. Quest, 51, 369-381.

Gyurcsik, N.C., Bray, S.R., \& Brittain, D.R. (2004). Coping with barriers to vigorous physical activity during transition to university. Family \& Community Health. $27(2), 130-142$.

Heath, G.W. \& Fentem, P.H. (1997). Physical activity among persons with disabilities-a public health perspective. In J.O. Holloszy (Ed.), Exercise and Sport Sciences Reviews. (pp.195-234). Baltimore, MD: Williams \& Wilkins.

Hedrick, B.N. \& Hedrick, S. (1993). The undiscovered athlete: A perspective on collegiate sports for persons with disabilities. Paper presented at the Conference of the Association of Higher Education and Disability. 1993, July.

Hildebrand, K.M. \& Johnson, D.J. (2001). Determinants of college physical activity class enrollment: Implications for high school physical education. Physical Educator, 58(1), 51-56.

Hughes, R.B., Nosek, M.A., Howland, C.A., Groff, J.Y., \& Mullen, P.D. (2003). Health promotion for women with physical disabilities: A pilot study. Rehabilitation Psychology. 48(3), 182-188. 
Katula, J.A., Blissmer, B.J., \& McAuley, E. (1999). Exercise intensity and self-efficacy effects on anxiety reduction in healthy, older adults. Journal of Behavioral Medicine, 22(3), 233-147.

Kinne, S., Patrick, D.L., \& Maher, E.J. (1999). Correlates of exercise maintenance among people with mobility impairments. Disability and Rehabilitation, 21(1), $15-22$.

Kosma, M., Cardinal, B.J. \& McCubbin, J.A. (2004). Predictors of physical activity stage of change among adults with physical disabilities. American Journal of Health Promotion, 19(2), 114-117.

Kosma, M., Cardinal, B.J. \& Rintala, P. (2002). Motivating individuals with disabilities to be physically active. Quest, 54, 116-132.

Lepore, M., Gayle, G.W., \& Stevens, S.F. (1998). Adapted Aquatics Programming, Champaign, IL: Human Kinetics.

MacGugan, K. (1979). Kl-Aikido for handicapped students at Leeward Community College: Theory and practice. (Doctoral dissertation, Nova University, 1979). (ED190185)

Maher, E.J., Kinne, S., \& Patrick, D.L. (1999). 'Finding a good thing': The use of quantitative and qualitative methods to evaluate an exercise class and promote exercise for adults with mobility impairments. Disability and Rehabilitation. 21(9), 438-447.

Marcus, B.H. \& Forsyth, L.H. Motivating People to Be Physically Active. (2003). Champaign, IL: Human Kinetics.

Marcus, B.H., Rakowski, W., \& Rossi, J.S. (1992a). Assessing motivational readiness 
and decision making for exercise. Health Psychology, 11(4), 257-261.

Marcus, B.H., Rossi, J.S., Selby, V.C., Niaura, R.S., \& Abrams, D.B. (1992b). The stages and processes of exercise adoption and maintenance in a worksite sample. Health Psychology, 11(6), 386-395.

Marcus, B.H., Selby, V.C., Niaura, R.S., \& Rossi, J.S. (1992c). Self-efficacy and the stages of exercise behavior change. Research Quarterly for Exercise and Sport, 63(1), 60-66.

Marshall, S. \& Biddle, S. (2001). The transtheoretical model of behavior change: A meta-analysis of applications to physical activity and exercise. Annals of Behavioral Medicine, 23, 229-246.

McAuley, E. (1992). The role of efficacy cognitions in the prediction of exercise behavior in middle-aged adults. Annals of Behavioral Medicine, 15(1), 65-88.

McAuley, E., Jerome, G.J., Marquez, D.X., Elavsky, S., \& Blissmer, B. (2003). Exercise self-efficacy in older adults: Social, affective, and behavioral influences. Annals of Behavioral Medicine, 25(1), 1-7.

Montgomery, D.L., Reid, G., \& Seidl, C. (1988). The effects of two physical fitness programs designed for mentally retarded adults. Canadian Journal of Sport Sciences, 13(1), 73-78.

Morgan, W.P. \& Dishman, R.K. (2001). Adherence to exercise and physical activity. Quest, 53, 277-278.

Nahas, M.V., Goldfine, B., \& Collins, M.A. (2003). Determinants of physical activity in adolescents and young adults: The basis for high school and college physical education to promote active lifestyles. Physical Educator, 60(1), 42-57. 
Nosek, M.A., Hughes, R.B., Swedlund, N., Taylor, H.B. \& Swank, P. (2003). Selfesteem and women with disabilities. Social Science \& Medicine, 56, 1737-1747.

Odette, F., Yoshida, K.K., Israel, P., Li, A., Ullman, D., Colontonio, A., Maclean, H., et al. (2003). Barriers to wellness activities for Canadian women with physical disabilities. Health Care for Women International, 24, 125-134.

Pinto, B.M. (1995). A stages of change approach to understanding college students' physical activity. Journal of American College Health, 44(1), 27-31.

Pitetti, K.H., Rimmer, J.H. \& Fernall, B. (1993). Physical fitness and adults with mental retardation: An overview of current research and future directions. Sports Medicine, 16(1), 23-56.

Plotnikoff, R.C., Blanchard, C., Hotz, S.B. \& Rhodes, R. (2001). Validation of the decisional balance scales in the exercise domain from the transtheoretical model: A longitudinal test. Measurement in Physical Education and Exercise Science, 5(4), 191-206.

Pollock, M.L., Miller, H.S., Linnerud, A.C., Laughridge, E., Coleman, E., \& Alexander, E. (1974). Arm pedaling as an endurance training regimen for the disabled. Archives of Physical Medicine and Rehabilitation, 55, 418-424.

Postsecondary Education Opportunity (March, 1999). Why College? Private Correlates of Educational Attainment. 81, 65-77.

Prochaska, J.O. \& DiClemente, C.C. (1983). Stages and processes of self-change of smoking: Toward an integrative model of change. Jounral of Consulting and Clinical Psychology. 51(3), 390-395.

Prochaska, J.O. \& Velicer, W.F. (1997). The transtheoretical model of health behavior 
change. American Journal of Health Promotion, 12(1), 38-48.

Ravesloot, C., Seekins, T., \& Walsh, J. (1997). A structural analysis of secondary conditions experienced by people with physical disabilities. Rehabilitation Psychology, 42(1), 3-16.

Ravesloot, C., Seekins, T., \& White, G. (2005). Living well with a disability health promotion intervention: Improved health status for consumers and lower costs for health care policymakers. Rehabilitation Psychology, 50(3), 239-245.

Ravesloot, C., Seekins, T., \& Young, Q. (1998). Health promotion for people with chronic illness and physical disabilities: The connection between health psychology and disability prevention. Clinical Psychology and Psychotherapy, 5, 76-85.

Rawls, J.J. \& Bean, W. California: An Interpretive History ( $8^{\text {th }}$ ed.). (2003). New York: McGraw-Hill.

Reid, G. (2000). Future directions of inquiry in adapted physical activity. Quest, 52, 369-381.

Resnick, B., Zimmerman, S.I., Orwig, D., Furstenberg, A., \& Magaziner, J. (2000). Outcome expectations for exercise scale: Utility and psychometrics. Journal of Gerontology, 55B(6), S352-S356.

Rimmer, J.H. (1999). Health promotion for people with disabilities: The emerging paradigm shift from disability prevention to prevention of secondary conditions. Physical Therapy, 79, 495-502.

Rimmer, J.H. \& Braddock, D. (2002). Health promotion for people with physical cognitive, and sensory disabilities: An emerging national priority. American 
Journal of Health Promotion, 16(4), 220-224.

Rimmer, J.H., Heller, T., Wang, E., \& Valerio, I. (2004). Improvements in physical fitness in adults with Down syndrome. American Journal on Mental Retardation, $109(2), 165-174$.

Salant, P. \& Dillman, D.A. How to Conduct Your Own Survey. (1994). New York: John Wiley \& Sons.

Sallis, J.F., Calfas, K.J., Alcaraz, J.E., Gehrman, C., \& Johnson, M.F. (1999a). Potential mediators of change in a physical activity promotion course for university students: Project Grad. Annals of Behavioral Medicine, 21(2), 149-158.

Sallis, J.F., Calfas, K.J., Nichols, J.F., Sarkin, J.A., Johnson, M.F., Caparosa, S., et al. (1999b). Evaluation of a university course to promote physical activity: Project GRAD. Research Quarterly for Exercise and Sport, 70(1), 1-10.

Sallis, J.F., Hovell, M.F., Hofstetter, C.R., Faucher, P., Elder, J.P., Blanchard, J., et al. (1989). A multivariate study of determinants of vigorous exercise in a community sample. Preventive Medicine, 18, 20-34.

Saracoglu, B., Minden, H., \& Wilchesky, M. (1989). The adjustment of students with learning disabilities to university and its relationship to self-esteem and selfefficacy. Journal of Learning Disabilities, 22(9), 590-592.

Seidler, T.L., Turner, E.T., \& Horine, L. (1993). Promoting active lifestyles through facilities and equipment-A look at children, seniors, and people with disabilities. Journal of Physical Education, Recreation, and Dance, 64(1), 33-64.

Steinhardt, M.A. \& Dishman, R.K. (1989). Reliability and validity of expected outcomes and barriers for habitual physical activity. Journal of Occupational Medicine, 
$31(6), 536-546$.

Stewart, C.C. (1988). Fitness for the disabled university student: Extending the mainstream. Physical Educator, 45(3), 139-146.

Stopka, C., Pomeranz, J., Siders, R., Dykes, M.K., \& Goodman, A. (1999). Transitional skills for wellness. Teaching Exceptional Children, 31(3), 6-11.

Sullum, J. \& Clark, M.M. (2000). Predictors of exercise relapse in a college population. Journal of American College Health, 48(4), 175-181.

Suminski, R.R., Petosa, R., Utter, A.C., \& Zhang, J.J. (2002b). Physical activity among ethnically diverse college students. Journal of American College Health, 51(2), 75-80.

Suomi, R., Surburg, P.R. \& Lecius, P. (1995). Effects of hydraulic resistance strength training on isokinetic measures of leg strength in men with mental retardation. Adapted Physical Activity Quarterly, 12, 377-387.

Thompson, G. (2003). The boomers are coming: Trends in older adult education. Canadian Journal of University Continuing Education, 29 (1), 9-27.

Tudor-Locke, C., Henderson, K.A., Wilcox, S., Cooper, R.S., Durstine, J.L., \& Ainsworth, B.E. (2003). In their own voices: Definitions and interpretations of physical activity. Women's Health Issues, 13, 194-199.

U. S. Department of Education, National Center for Education Statistics. (2003). The Condition of Education 2003 (NCES 2003-067). Retrieved on 01/24/06 from http://nces.ed.gov/fastfacts/display.asp?id=60

Van Vorst, J.G., Buckworth, J. \& Mattern, C. (2002). Physical self-concept and strength changes in college weight training classes. Research Quarterly for Exercise and 
Sport, 73(1), 113-117.

Warms, C.A., Belza, B.L., Whitney, J.D., Mitchell, P.H., \& Stiens, S.A. (2004).

Lifestyle physical activity for individuals with spinal cord injury: A pilot study. American Journal of Health Promotion, 18(4), 288-291.

Weil, E., Wachterman, M., McCarthy, E.P., Davis, R.B., O’Day, B., Iezzoni, L.I. \& Wee, C.C. (2002). Obesity among adults with disabling conditions. Journal of the American Medical Association, 288(10), 1265-1268.

Wilber, N., Mitra M., Walker, D.K., Allen, D., Meyers, A.R., \& Tupper P. (2002).

Disability as a public health issue: Findings and reflections from the Massachusetts Survey of Secondary Conditions. The Milbank Quarterly, 80(2), $393-421$. 
Appendix A

Letter to DSPS Directors 
July 12,2006

Dear

I hope this letter finds you enjoying a nice summer. You may remember I have been working on my dissertation at the University of San Diego.

For the past several years I have taught adapted physical education at community colleges in San Diego and Imperial Counties. It has been a rewarding experience, allowing me to encourage students with disabilities to improve their physical fitness levels and provide them with tools to increase their exercise self-efficacy. I have become aware that many students eligible to enroll in adapted physical education courses either avoid enrolling in them or delay enrollment. I would like to assess reasons for this so that I may become more aware of what can be done to encourage exercise in and out of the school environment. I am writing to request your support in collecting survey data from some of the students enrolled in your DSS program.

Currently, I am a doctoral student at the University of San Diego and preparing my dissertation entitled "Adapted Physical Education Enrollment Issues and Exercise Mediators for Students with Disabilities in San Diego County Community Colleges." Approval has been awarded by my dissertation committee and the Institutional Review Board at the University of San Diego. You may call my adviser, Dr. Fred Galloway, with questions at 619.260.7435. As part of my dissertation, I would like to survey students with physical and sensory disabilities in all of San Diego County's community colleges. I realize you and your staff are extremely busy so I plan to do the bulk of the work myself. I will require a point person within the DSS office to assist with mailing labels. I will pay for all printing and mailing costs. And, of course, all efforts will be taken to ensure confidentiality of students.

I sincerely hope you will agree to support my work. I believe the data may be interesting, if not useful, to your department. I hope to present my findings at a future Region 10 Coordinators' Meeting. I will contact you within the next week to discuss this opportunity, determine what concerns you have, and further discuss implementation of the research. Please feel free to contact me in the interim.

Best regards,

Toni Pfister, MS toni.pfister@imperial.edu

619.281.8664 home 760.355 .6546 work 
Appendix B

Letter Inviting Student to Complete Survey 
Dear College Student:

August 15, 2006

I would like to introduce myself to you. My name is Toni Pfister and I am a student at the University of San Diego in the School of Leadership and Education Sciences. I would like your help in completing a questionnaire that is part of my doctoral project. You have been selected because you are registered with the Disability Support Services (DSS) at College. Although the College DSS Department supports my research and helped send out this letter, your responses will be anonymous to me and to your school, and will not impact your school services. Your participation is completely voluntary. I want to learn more about your views on exercise participation and classes for students with disabilities. I also want to understand why some students enroll in adapted physical education while others do not. Adapted physical education includes P.E. classes for individuals with disabilities and chronic health problems. Your comments and viewpoints are very important and may be used to improve future programs and class offerings for students with disabilities in community colleges. The questionnaire consists of about 45 questions about you, and your thoughts on and experiences with exercise and physical education. The questionnaire will take approximately 15 minutes to complete.

You may complete this questionnaire by using any computer and connecting to the surveymonkey.com website (see instructions at bottom of this page). You may be able to use a computer at the High Tech Center or in the computer labs at Or if you prefer, I will be available to help you on Friday, September 8 from 1:00 - 3:00 pm at the DSS office. If you would prefer to have a paper survey mailed to you, assistance when completing the survey, or the survey printed in an alternate format please contact me with questions or to schedule an appointment at 619)876-0801 or tonipfi@hotmail.com.

Your participation in the survey is completely voluntary. Your responses will be kept private and not given out to school representatives. I am the only individual who will have access to individual responses. If you have any questions about the survey you may call me at the number above or my advisor, Dr. Fred Galloway, at The University of San Diego at 619.260.7435

Your participation is greatly valued and appreciated. My study cannot be completed without help from students like you. Thank you in advance for agreeing to participate.

Best regards,

Toni Pfister

\section{Instructions:}

1. Go to computer.

2. Go onto the internet. 
3. Go to this link:

http://www.surveymonkey.com/s.asp? u=377192464188

4. Follow the directions on your computer screen to complete the survey 5. If you have trouble, please contact Toni at 619)876-0801 for assistance. 
Appendix C

The Survey 
Thank you for taking the time to complete this survey.

Adapted physical education, or APE, is a physical education class in which a person with a disability or chronic health impairment can learn physical education concepts and develop physical skills.

1. Consider all community colleges, state universities, and private colleges you may have attended. How many, if any, standard (non-adapted) physical Education classes have you completed at the college level?

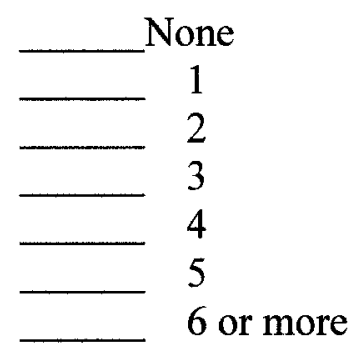

2. Adapted physical education is a physical education class in which a person with a disability or chronic health impairment can learn physical education concepts and develop physical skills.

Have you ever completed an adapted physical education (APE) class at this college or any college? (Please check "Yes" or "No")

If "No" $\rightarrow$ (Now, please move forward to Item \#3a on the next page.)

If "Yes" $\rightarrow \rightarrow$ How many adapted physical education classes have you completed at the college level? Consider all community colleges, state universities, and private colleges.

Please describe the reason(s) you took an APE course.

(Now, please skip ahead to Item \#4 on Page 3) 
3a. Please read the whole list and then put a check by the three most important reasons why you have NOT taken a college-level Adapted Physical Education (APE) class.

A. I exercise on my own

B. I don't like to exercise

C. No adapted PE classes are offered at my school

D. I am not aware of adapted PE classes at my school

E. I do not believe there would be activities for me to do

F. I would not enjoy the activities

G. I do not need to take APE, I attend regular PE classes

H. I had not previously heard of adapted PE

I. I would not feel comfortable exercising with others

J. I would not have the assistance that I need

K. APE classes always conflict with my schedule

L. I tried an APE course and did not care for it (please explain):

M. I don't want to take a class with other disabled students

N. I would not be comfortable changing clothes in front of others

O. I would need extra assistance (changing clothes, help in the exercise room)

P. I am afraid of getting injured

Q. Other (please explain:

3b. To complete this item please use your answers from the question above. List the letter corresponding to your most important reason for not taking an APE class first; then list your second most important reason; and then list your third most important reason for not taking an APE class.

Your answers may look something like this:

1st most important reason - "B"

2nd most important reason - "G"

3rd most important reason - "Other"

1st most important reason

2nd most important reason

3rd most important reason

(Now Please Go to Item \# 4 on the next page) 


\section{Stage of Exercise Scale}

4. Directions: Please CIRCLE the number that best describes your present exercise behavior. "Regular exercise" equals 20 minutes or more of exercise on three or more days per week (walking, swimming, hand cycling, etc.)

0 I presently do not exercise and do not plan to start exercising in the next 6 months

1 I presently do not exercise, but I have been thinking about starting to exercise within the next 6 months only begun doing so within the past 6 months been doing so for longer than 6 months

5. Please CIRCLE the letter that best describes your interest in enrolling in an ADAPTED PHYSICAL EDUCATION class in the future.
A I do not ever plan on enrolling in an adapted physical education class
B I am considering enrolling in an adapted physical education class in the future
C I will definitely enroll in an adapted physical education class in the future 
D If an adapted physical education class is available at my school, I will enroll in it.

E I do not know if I will ever enroll in an adapted physical education class.

6. Please CIRCLE the letter best describing your interest in enrolling in a REGULAR PHYSICAL EDUCATION (not an adapted PE class):

A I do NOT ever plan to enroll in a regular physical education class

B I am considering enrolling in a regular physical education class in the future

C I will definitely enroll in a regular physical education class in the future

D I do not know if I will ever enroll in a regular physical education class

\section{Self-Efficacy Scale}

Physical activity or exercise includes activities such as walking briskly, jogging, bicycling, hand cycling, swimming, wheelchair rolling, or any other activity in which the exertion is at least as intense as these activities.

Circle the number that indicates how confident you are that you would be physically active in each of the following situations

Scale

$1=$ not at all confident

2 = slightly confident

$3=$ moderately confident

$4=$ very confident

5 = extremely confident

7. When I am tired. 


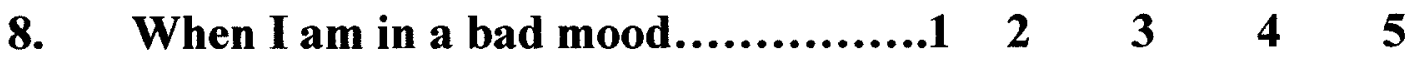

9. When I feel I don't have time............ 2 2 $3 \quad 4 \quad 5$

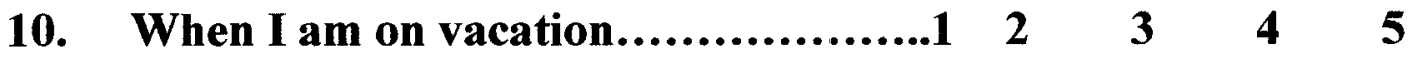

11. When it is raining (or very cold)........1 2 2 $34 \quad 4 \quad 5$ Outcome Expectations for Exercise

The following are statements about the benefits of exercise (such as walking, jogging, swimming, hand cycling, stretching or lifting weights).

Circle the statement that best indicates how strongly you agree or disagree with how these statements relate to you.

12. Exercise makes me feel better physically.

Strongly Disagree Disagree Neutral Agree Strongly Agree

13. Exercise makes my mood better in general.

Strongly Disagree Disagree Neutral Agree Strongly Agree

14. Exercise helps me feel less tired.

Strongly Disagree Disagree Neutral Agree Strongly Agree

15. Exercise makes my muscles stronger.

Strongly Disagree Disagree Neutral Agree Strongly Agree 
16. Exercise is an activity I enjoy doing.

Strongly Disagree Disagree Neutral Agree Strongly Agree

17. Exercise gives me a sense of personal accomplishment.

Strongly Disagree Disagree Neutral Agree Strongly Agree

18. Exercise makes me more alert mentally.

Strongly Disagree Disagree Neutral Agree Strongly Agree

19. Exercise improves my endurance in performing my daily activities (such as personal care, cooking, shopping, light cleaning, taking out garbage).

Strongly Disagree Disagree Neutral Agree Strongly Agree

20. Exercise helps to strengthen my bones.

Strongly Disagree Disagree Neutral Agree Strongly Agree

21. Exercise helps me get to a healthy weight or maintain my weight.

Strongly Disagree Disagree Neutral Agree Strongly Agree 


\section{DECISIONAL BALANCE SCALE}

Physical activity or exercise includes activities such as walking briskly, jogging, hand cycling, swimming, wheel chair rolling, or any other activity in which the exertion is at least as intense as these activities. In each case below, think about how you feel right now, not how you have felt in the past or would like to feel.

Each of these factors may affect one's decision to be physically active. Circle the statement that best indicates the degree to which you agree or disagree with these statements

22. I would have more energy for my family and friends if I were regularly physically active

Strongly Disagree Disagree Neutral Agree Strongly Agree

23. Regular physical activity would help me relieve tension Strongly Disagree Disagree Neutral Agree Strongly Agree

24. I think I would be too tired to do my daily work after being physically active

Strongly Disagree Disagree Neutral Agree Strongly Agree

25. I would feel more confident if I were regularly physically active Strongly Disagree Disagree Neutral Agree Strongly Agree

26. I would sleep more soundly if I were regularly physically active Strongly Disagree Disagree Neutral Agree Strongly Agree 
27. I would feel good about myself if I kept my commitment to be regularly physically active

Strongly Disagree Disagree Neutral Agree Strongly Agree

28. I would find it difficult to find a physical activity that I enjoy and that is not affected by bad weather

Strongly Disagree Disagree Neutral Agree Strongly Agree

29. I would like my body better if I were regularly physically active Strongly Disagree Disagree Neutral Agree Strongly Agree

30. It would be easier for me to perform routine physical tasks if I were regularly physically active

Strongly Disagree Disagree Neutral Agree Strongly Agree

31. I would feel less stressed if I were regularly physically active

Strongly Disagree Disagree Neutral Agree Strongly Agree

32. I feel uncomfortable when I am physically active because I get out of breath and my heart beats very fast

Strongly Disagree Disagree Neutral Agree Strongly Agree

33. I would feel more comfortable with my body if I were regularly physically active

Strongly Disagree Disagree Neutral Agree Strongly Agree 
34. Regular physical activity would take too much of my time

Strongly Disagree Disagree Neutral Agree Strongly Agree

35. Regular physical activity would help me have a more positive outlook on life

Strongly Disagree Disagree Neutral Agree Strongly Agree

36. I would have less time for my family and friends if I were regularly physically active

Strongly Disagree Disagree Neutral Agree Strongly Agree

37. At the end of the day, I am too exhausted to be physically active Strongly Disagree Disagree Neutral Agree Strongly Agree 
38. Including any Spring, Fall, Winter, or Summer semesters, how many semesters have you completed of college? If you have attended a college on the quarter system, please consider those quarters to be semesters for the purpose of this question. Do not worry about going to school part-time or full-time, just add up the number of semesters you have attended any type of college.

$1-2$ semesters

$3-4$ semesters

5 -6 semesters

7 -8 semesters

9 or more semesters

Other (please specify)

39. This information will be kept strictly confidential and your response is voluntary. It will be helpful to the researcher to better understand what type of disability or chronic illness you have.

Here is a list used by the DSPS Department. What is the name of the primary disability you are being served for by DSPS?

Mobility impairment

Visual impairment

Other disability. Please explain 
40. At what age did your disability or disease first occur?

At birth

0 - 10 years old

$11-20$ years old

$21-30$ years old

$31-40$ years old

$41-50$ years old

$51-60$ years old

$61-70$ years old

$71+$ years old

Other (please specify)

41. What year were you born?

42. What gender are you? (Please check one.)

Female

Male 
43. Please check the box(es) that best describe your ethnicity

White (Non-Hispanic) Hispanic, Mexican, Latina/Latino Black, African American American Indian or Alaska Native Asian Native Hawaiian or other Pacific Islander Other (Specify)

44. Please describe any ideas you have that would encourage students to enroll in an adapted physical education class.

45. Please list any comments you have regarding your experience completing this survey.

Your time and effort in completing the survey is greatly appreciated. Please contact Toni Pfister at tonipfi@hotmail.com or 619)876.0801 with any questions or concerns or if you would like help with any part of this survey.

Thank you for taking the time to complete this survey. 


\section{Appendix D}

The Survey with Distribution of Responses 


\section{THE SURVEY}

Thank you for taking the time to complete this survey.

Adapted physical education, or APE, is a physical education class in which a person with a disability or chronic health impairment can learn physical education concepts and develop physical skills.

1. Consider all community colleges, state universities, and private colleges you may have attended. How many, if any, standard (non-adapted) physical education classes have you completed at the college level?

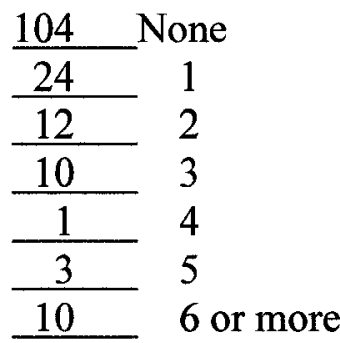

2. Adapted physical education is a physical education class in which a person with a disability or chronic health impairment can learn physical education concepts and develop physical skills.

Have you ever completed an adapted physical education (APE) class at this college or any college? (Please check "Yes" or "No")
128 If "No" $\rightarrow$ (Now, please move forward to Item \#3a on the next page.)
36 If "Yes" $\rightarrow \rightarrow$ How many adapted physical education classes have you completed at the college level? Consider all community colleges, state universities, and private colleges.

Please describe the reason(s) you took an APE course.

(Now, please skip ahead to Item \#4 on Page 3) 
3a. ${ }^{1}$ Please read the whole list and then put a check by the three most important reasons why you have NOT taken a college-level Adapted Physical Education (APE) class.

A. I exercise on my own

B. I don't like to exercise

C. No adapted PE classes are offered at my school

D. I am not aware of adapted PE classes at my school

E. I do not believe there would be activities for me to do

F. I would not enjoy the activities

G. I do not need to take APE, I attend regular PE classes

H. I had not previously heard of adapted PE

I. I would not feel comfortable exercising with others

J. I would not have the assistance that I need

K. APE classes always conflict with my schedule

L. I tried an APE course and did not care for it (please explain):

M. I don't want to take a class with other disabled students

N. I would not be comfortable changing clothes in front of others

O. I would need extra assistance (changing clothes, help in the exercise room)

P. I am afraid of getting injured

Q. Other (please explain:

3b. To complete this item please use your answers from the question above. List the letter corresponding to your most important reason for not taking an APE class first; then list your second most important reason; and then list your third most important reason for not taking an APE class.

Your answers may look something like this:

1 st most important reason - "B"

2nd most important reason - "G"

3rd most important reason - "Other"

1st most important reason

2nd most important reason

3rd most important reason

${ }^{1}$ Frequency distributions for item 3 can be located in Appendix E.

(Now Please Go to Item \# 4 on the next page) 


\section{Stage of Exercise Scale}

4. Directions: Please CIRCLE the number that best describes your present exercise behavior. "Regular exercise" equals 20 minutes or more of exercise on three or more days per week (walking, swimming, hand cycling, etc.)

(10) 0 I presently do not exercise and do not plan to start exercising in the next 6 months

(27) 1

I presently do not exercise, but I have been thinking about starting to exercise within the next 6 months

(52) 2 I presently get some exercise, but not regularly

(24) 3 I presently exercise on a regular basis, but I have only begun doing so within the past 6 months

(49) 4 I presently exercise on a regular basis and have been doing so for longer than 6 months

(1) Missing

5. Please CIRCLE the letter that best describes your interest in enrolling in an ADAPTED PHYSICAL EDUCATION class in the future.

(58) A I do not ever plan on enrolling in an adapted physical education class

(24) B I am considering enrolling in an adapted physical education class in the future

(27) C I will definitely enroll in an adapted physical education class in the future

(23) D If an adapted physical education class is available at my school, I will enroll in it.

(34) E I do not know if I will ever enroll in an adapted physical education class.

(1) Missing 
6. Please CIRCLE the letter best describing your interest in enrolling in a REGULAR PHYSICAL EDUCATION (not an adapted PE class):

(51) A I do NOT ever plan to enroll in a regular physical education class

(43) B I am considering enrolling in a regular physical education class in the future

(29) C I will definitely enroll in an regular physical education class in the future

(40) D I do not know if I will ever enroll in a regular physical education class

(1) Missing

\section{Self-Efficacy Scale}

Physical activity or exercise includes activities such as walking briskly, jogging, bicycling, hand cycling, swimming, wheelchair rolling, or any other activity in which the exertion is at least as intense as these activities.

Circle the number that indicates how confident you are that you would be physically active in each of the following situations

Scale

$$
\begin{aligned}
& 1=\text { not at all confident } \\
& 2=\text { slightly confident } \\
& 3=\text { moderately confident } \\
& 4=\text { very confident } \\
& 5=\text { extremely confident }
\end{aligned}
$$

7. When I am tired

$\begin{array}{llll}\text { (43) } \quad \text { (53) (40) (12) (9) } \quad \text { (6) missing } & \end{array}$

$\begin{array}{lllll}1 & 2 & 3 & 4 & 5\end{array}$

(28) (32) (49) (34) (15)(6) missing

8. When I am in a bad mood............ 2 . 3 4 5

(50) (40) (42) (13) (11)(8) missing

9. When I feel I don't have time......... 2 2 344

10. When I am on vacation...............

$\begin{array}{lllll}\text { (36) } & \text { (36) } & \text { (34) } & \text { (29) } & \text { (23)(8) missing }\end{array}$

11. When it is raining or very cold......1 2 3 4 \begin{tabular}{llll}
5 \\
\hline
\end{tabular}

\section{Outcome Expectations for Exercise}


The following are statements about the benefits of exercise (such as walking, jogging, swimming, hand cycling, stretching or lifting weights).

Circle the statement that best indicates how strongly you agree or disagree with how these statements relate to you.

12. Exercise makes me feel better physically.
(4)
(2)
(18)
(59)
(76)
(5) Missing

Strongly Disagree

Disagree

Neutral

Agree

Strongly Agree

13. Exercise makes my mood better in general.
(3)
(4)
(29)
(64)
(59)
(5) Missing

Strongly Disagree

Disagree Neutral

Agree

14. Exercise helps me feel less tired.
(9)
(20)
(46)
(50)
Agree
(33)
(6) Missing
Disagree
Neutral
Strongly Agree

Strongly Disagree

15. Exercise makes my muscles stronger.
(4)
(6)
(17)
(64)
(68)
(5) Missing

Strongly Disagree

Disagree Neutral

Agree

16. Exercise is an activity I enjoy doing.
(7)
(17)
(46)
(42)

Strongly Disagree

Disagree Neutral

Agree

(44)

(8) Missing

Strongly Agree

17. Exercise gives me a sense of personal accomplishment.
(2)
(10)
(27)
(57)
(63)
(5) Missing

Strongly Disagree

Disagree

Neutral

Agree

Strongly Agree

18. Exercise makes me more alert mentally.
(6)
(10)
(43)
(55)
(7) Missing

Strongly Disagree Disagree Neutral Agree Strongly Agree

19. Exercise improves my endurance in performing my daily activities (such as personal care, cooking, shopping, light cleaning, taking out garbage).
(6)
(7)
(34)
(54)
(58)
(5) Missing

Strongly Disagree Disagree Neutral Agree Strongly Agree

20. Exercise helps to strengthen my bones.
(2)
(6)
(36)
(53)
(62)
(5) Missing

Agree

Strongly Disagree

Disagree Neutral

Strongly Agree

21. Exercise helps me get to a healthy weight or maintain my weight. 
(2)

Strongly Disagree
(3)

Disagree
(24)

Neutral
(56)

Agree
(72) (7) Missing

Strongly Agree

\section{DECISIONAL BALANCE SCALE}

Physical activity or exercise includes activities such as walking briskly, jogging, hand cycling, swimming, wheel chair rolling, or any other activity in which the exertion is at least as intense as these activities. In each case below, think about how you feel right now, not how you have felt in the past or would like to feel.

Each of these factors may affect one's decision to be physically active. Circle the statement that best indicates the degree to which you agree or disagree with these statements

22. I would have more energy for my family and friends if I were regularly physically active
(4)
(10)
(39)
(62)
(36) (13) Missing

Strongly Disagree Disagree Neutral Agree Strongly Agree

Strongly Disagree $\quad$ Disagree $\quad$ Neutral Agree $\quad$ Strongly Agree

23. Regular physical activity would help me relieve tension
(3)
(6)
(19)
(69)
(54) (13) Missing

Strongly Disagree

Disagree Neutral

Agree

Strongly Agree

24. I think I would be too tired to do my daily work after being physically active
(20)
(52)
(42)
(24)
(12) (14) Missing

Strongly Disagree

Disagree Neutral

Agree

Strongly Agree

25. I would feel more confident if I were regularly physically active
(3)
(3)
(34)
(61)
(49) (14) Missing
Disagree
Neutral
Agree
Strongly Agree

Strongly Disagree

26. I would sleep more soundly if I were regularly physically active
(8)
(5)
(29)
(66)
(43) (13) Missing

Strongly Disagree

Disagree Neutral

Agree

Strongly Agree

27. I would feel good about myself if I kept my commitment to be regularly physically active
(4)
(2)
(26)
(60)
(58) (14) Missing
Agree
Strongly Agree

Strongly Disagree

Disagree Neutral

28. I would find it difficult to find a physical activity that I enjoy and that is not 
affected by bad weather
(31)
(50)
(29)
(29)
(12) (13) Missing

Strongly Disagree

Disagree

Neutral

Agree

Strongly Agree

29. I would like my body better if I were regularly physically active
(3)
(12)
(25)
(52)
(57) (15) Missing

Strongly Disagree Disagree Neutral Agree Strongly Agree

30. It would be easier for me to perform routine physical tasks if I were regularly physically active
(5)
(10)
(31)
(61)
(44) (13) Missing

Strongly Disagree Disagree Neutral Agree Strongly Agree

31. I would feel less stressed if I were regularly physically active
(5)
(9)
(32)
(63)
(41) (14) Missing

Strongly Disagree

Disagree Neutral

Agree

Strongly Agree

32. I feel uncomfortable when I am physically active because I get out of breath and my heart beats very fast
(37)
(38)
(36)
(30)
(9) (14) Missing

Strongly Disagree Disagree Neutral Agree $\quad$ Strongly Agree

33. Regular physical activity would take too much of my time
(20)
(59)
(43)
(25)
(4) (13) Missing

Strongly Disagree Disagree Neutral Agree Strongly Agree

34. Regular physical activity would help me have a more positive outlook on life
(7)
(6)
(27)
(79)
(32) (13) Missing

Strongly Disagree

Disagree Neutral

Agree

Strongly Agree

35. I would have less time for my family and friends if I were regularly physically active
(25)
(64)
(39)
(18)
(6) (12) Missing

Strongly Disagree

Disagree Neutral

Agree

Strongly Agree

36. At the end of the day, I am too exhausted to be physically active
(17)
(35)
(39)
(37)
(23) (13) Missing
Disagree Neutral
Agree
Strongly Agree

Strongly Disagree

37. I would feel more comfortable with my body if I were regularly physically active
(4)
(6)
(24)
(69)
(48) (13) Missing

Strongly Disagree

Disagree Neutral

Agree

Strongly Agree 
38. Including any Spring, Fall, Winter, or Summer semesters, how many semesters have you completed of college? If you have attended a college on the quarter system, please consider those quarters to be semesters for the purpose of this question. Do not worry about going to school part-time or full-time, just add up the number of semesters you have attended any type of college.

$34 \quad 1-2$ semesters

$37 \quad 3-4$ semesters

$30 \quad 5-6$ semesters

$13 \quad 7-8$ semesters

$35 \quad 9$ or more semesters

39. This information will be kept strictly confidential and your response is voluntary. It will be helpful to the researcher to better understand what type of disability or chronic illness you have.

Here is a list used by the DSPS Department. What is the name of the primary disability you are being served for by DSPS?

39 Mobility impairment

12 Visual impairment

97 Other disability. Please explain

40. At what age did your disability or disease first occur?

30 At birth

$28 \quad 0-10$ years old

$28 \quad 11-20$ years old

$20 \quad 21-30$ years old

$19 \quad 31-40$ years old

$15 \quad 41-50$ years old

$8 \quad 51-60$ years old 

$71+$ years old

\section{What year were you born?}

42. What gender are you? (Please check one.)

\begin{tabular}{cl}
87 & Female \\
\hline 61 & Male \\
\hline 16 & Missing
\end{tabular}

43. Please check the box(es) that best describe your ethnicity

\begin{tabular}{cl}
91 & White (Non-Hispanic) \\
\hline 34 & Hispanic, Mexican, Latina/Latino \\
\hline 14 & Black, African American \\
\hline 4 & American Indian or Alaska Native \\
\hline 12 & Asian \\
\hline 4 & Native Hawaiian or other Pacific Islander \\
\hline 19 & Other (Specify) \\
\hline
\end{tabular}

44. Please describe any ideas you have that would encourage students to enroll in an adapted physical education class.

45. Please list any comments you have regarding your experience completing this survey.

Your time and effort in completing the survey is greatly appreciated. Please contact Toni Pfister at tonipfi@hotmail.com or 619)876.0801 with any questions or concerns or if you would like help with any part of this survey.

Thank you for taking the time to complete this survey. 
Appendix E

Reasons for APE Avoidance 


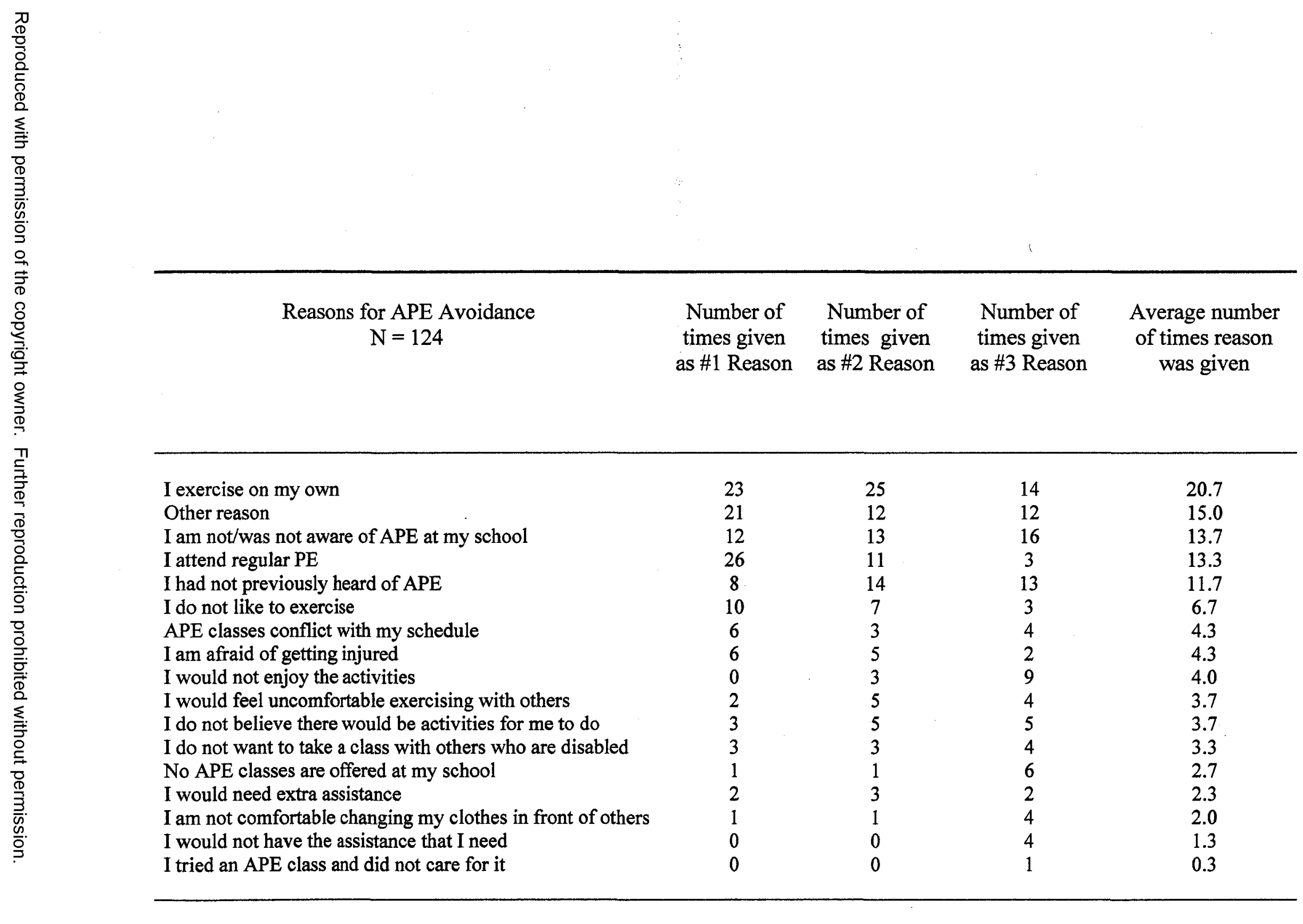

I exercise on my own

I am not/was not aware of APE at my school

I attend regular PE

Thad not previously heard of APE

I do not believe there would be activities for me to do

times given times given

times given

was given

school

I am not comfortable changing my clothes in front of others

I would not have the assistance that I need

tried an APE class and did not care for it 